\title{
Cement Augmentation in a Thoracolumbar Fracture Model
}

\author{
by \\ Alexander C. Disch \\ Thesis in partial fulfillment of the degree of \\ Doctor of Philosophy (PhD) \\ Musculoskeletal Science
}

Medical University of Innsbruck

Supervisor: Assoz.-Prof. Dipl.-Ing. Dr. W. Schmölz

1st committee member: Universitäts-Professor Dr. M. Blauth

2nd committee member: Professor Dr. C. Knop

Internal reviewer:

External reviewer:
Privat-Dozent Dr. D. Krappinger, PhD

Universitäts-Professor Dr. G. Matziolis

Innsbruck, 01.07.2015 


\section{Acknowledgments}

I would like to express my special appreciation and thanks here to my advisor, Assoz.-Prof. Dipl.-Ing. Dr. Werner Schmölz, who has been a tremendous mentor and friend for me. I would like to thank him for encouraging my research and for allowing me to grow as a research scientist. I would also like to thank Universitäts-Professor Dr. Klaus-Dieter Schaser, who has provided constant support for my clinical and scientific career. His advice on both has been priceless. I would also like to thank the members of the committee for serving, despite difficulty: Universitäts-Professor Dr. Michael Blauth for his strong support and engagement during the completion of the $\mathrm{PhD}$ and Professor Dr. Christian Knop for his help and advice in solving clinical and research problems. Special thanks go to Assoz.-Professor Dr. Christian Haid for his kind help and support in all matters regarding the PhD research.

I would particularly like to thank the physicians, nurses and nurse assistants in the Department of Trauma Surgery at the University Medical Center in Innsbruck.

Special thanks also go to my family. Words cannot express how grateful I am to my mother-in law, father-in-law, mother, and father for all of the sacrifices they have made on my behalf. Their prayers for me have sustained me thus far. I would also like to thank all of my friends who supported me in writing and encouraged me to continue striving towards the goal. Finally, I would like express appreciation to my beloved wife Inken, who has always been my support in moments when there was no one to answer my queries. 


\section{Table of Contents}

ACKNOWLEDGMENTS

TABLE OF CONTENTS

ABSTRACT

INTRODUCTION

Prologue

Thoracolumbar Spinal Anatomy

Mechanical Concepts and Biomechanical Application

Mechanical Properties of the Thoracolumbar Spine

Pathological Spinal Column Defects

Stabilization of the Thoracolumbar Spine

Vertebral Body Augmentation

Measuring Primary and Secondary Stability in Biomechanical In-Vitro Experiments

Purpose of the Study

MATERIALS AND METHODS

Specimens

Preparation of the Specimens

Wedge Fracture Creation

Fracture Treatment with Augmentation Techniques

Flexibility Testing in a Spine Simulator

Cyclic Loading

Test Sequences

Recorded Data 
$\begin{array}{lr}\text { Radiographic Investigation } & 48\end{array}$

$\begin{array}{lr}\text { Statistical Analysis } & 50\end{array}$

$\begin{array}{ll}\text { RESULTS } & 51\end{array}$

$\begin{array}{ll}\text { Flexibility Tests (ROM) } & 51\end{array}$

Elastic Displacement and Height Loss during Cyclic Loading 52

$\begin{array}{ll}\text { Radiographic Investigations } & 54\end{array}$

$\begin{array}{lr}\text { DISCUSSION } & 56\end{array}$

$\begin{array}{lc}\text { REFERENCES } & 63\end{array}$

$\begin{array}{lr}\text { LEGENDS TO FIGURES } & 78\end{array}$

$\begin{array}{lr}\text { LEGENDS TO TABLES } & 82\end{array}$

$\begin{array}{lr}\text { ABBREVIATIONS } & 83\end{array}$

$\begin{array}{lr}\text { PUBLICATION } & 85\end{array}$

$\begin{array}{lr}\text { DECLARATION OF AUTHORSHIP } & 92\end{array}$ 


\section{Abstract}

Study Design: In-vitro biomechanical investigation.

Objective: To assess differences in kyphosis after balloon kyphoplasty (BKP) or vertebral body stenting (VBS).

Summary of Background Data: Cement augmentation techniques allow early mobilization in patients with osteoporotic thoracolumbar fractures. Biomechanically, the grade of reduction and preservation are as important as in nonosteoporotic fractures. With BKP, it is as yet unclear whether balloon deflation has negative effects on the reduction and whether specific combinations of materials may be capable of maintaining the reduction.

Methods: Twelve bisegmental human thoracolumbar specimens $(6 \times \mathrm{T} 12-$ L2, $6 \times$ L3-L5; age at death $76.3 \mathrm{y}$, range $63-89 \mathrm{y}$; female-male ratio $3: 3$; bone mineral density $76.8 \mathrm{mg} / \mathrm{cm}^{3}$, SD $10.9 \mathrm{mg} / \mathrm{cm}^{3}$ ) were tested in a spine simulator with pure moments of $7.5 \mathrm{Nm}$ to assess primary and secondary stability. Following flexibility testing of the intact specimens, an eccentric compression force induced standardized fractures, which were reduced using either BKP or VBS against a flexional moment of $2.5 \mathrm{Nm}$. Primary and secondary stability were assessed using range of motion (ROM) in a spine tester. The specimens were tested after each of three periods of cyclic flexion loading. The kyphotic angle of the index vertebra was measured radiographically.

Results: The two techniques achieved comparable reduction against a relatively high bending moment in this model. Neither technique restored the 
stability of the intact state; with increasing loads, the ROM continuously declined to the level of the fractured specimen. During cyclic loading, height loss and elastic displacement showed similar results with the two augmentation techniques. Although the deflation effect on the kyphotic angle was lower with VBS $(P \leq 0.05)$, there were no significant differences between the techniques relative to angle restoration.

Conclusions: Both augmentation techniques are able to restore vertebral body height following thoracolumbar fractures. The deflation effect on the kyphotic angle was less with VBS than with BKP. High flexion moments during implantation limit the effectiveness of reduction using cement augmentation methods. 


\section{Introduction}

\section{Prologue}

Instability is one of the fundamental pathological conditions that occur in the course of spinal diseases. It arises through different pathogenetic pathways that lead to a breakdown of segmental mechanical properties. The most common causes of segmental spinal instability are degenerative disease (1), trauma (2), and spinal tumors $(3,4)$. A clear definition of spinal instability is lacking in the current medical literature. According to Panjabi, "clinical instability is a significant decrease in the capacity of the stabilizing system of the spine to maintain the intervertebral neutral zones within the physiological limits, so that there is no neurological dysfunction, no major deformity and no incapacitating pain" (5-8).

Scenarios of this type and reconstructions of them need to be investigated in order to obtain sufficient information concerning the necessity and extent of surgical interventions in patients with spinal instability, particularly in the thoracolumbar spine. Simulating mechanical spinal insufficiencies and confirming the stabilizing effects of reconstructions in defect situations is one of the major tasks for biomechanical testing. Examinations in animal models are difficult to conduct due to the absence of standardization and lack of comparability with humans, but finite-element simulations are also necessarily simplifications of the actual physiological situation. Biomechanical in-vitro testing using human specimens is available as an alternative. Such testing is now being carried out on the basis of internationally approved standards (911), leading to good comparability and reliability in the results obtained. The 
use of spine simulators is a basic requirement for adequate investigation here. Spine simulators make it possible to apply loads to the specimens using pure moments along the three main motion planes in the spine. In combination with a cyclic loading regimen, this allows conclusions to be drawn regarding the primary and secondary stability results $(12,13)$.

\section{Thoracolumbar Spinal Anatomy}

The human spinal column consists of seven cervical, 12 thoracic, five to six lumbar vertebrae and the sacrum, extending from the occiput of the skull to the sacroiliac joint and pelvis. Spinal motion is made possible by a chain of functional spinal units (FSU) that consist of two adjoining vertebrae, the intervertebral disc and the corresponding ligamentous structures (anterior and posterior longitudinal ligament, interspinous/supraspinous ligament, ligamentum flavum). Motion is made possible here through a tripartite joint represented by the intervertebral disc and the two facet joints (14).

The disc consists of the surrounding outer and inner anulus fibrosus and a core, the nucleus pulposus. Functionally, the disc has a high capacity to bind water, due to the biochemical composition of the proteoglycans that are mainly involved. Together with the orientation of fibers relative to the neighboring endplates, the intervertebral disc is able to resist loads and distribute them in an axial direction (14).

Along the spinal column, the orientation of the facet joints varies significantly on the coronal and sagittal plane from the cervical spine to the thoracic spine and lumbar spine. In the lumbar spine, facet joint function allows a 
comparatively wide range of motion (ROM) in flexion/extension, lateral bending and rotation.

Spinal motion is made possible through the agonism and antagonism of different muscle groups. The muscles of the trunk, shoulder girdle and pelvis act on the spinal column. The thoracic and abdominal muscles are able - in equilibrium with the structures of the thoracic and abdominal cavity - to transfer compressive loads directly to the pelvis and reduce loading on the spinal column. Different muscle groups are mainly involved in the spinal column itself: the intertransverse muscles and anterolateral muscles, and most importantly the posterior muscle group. The latter consists of the following parts (Figure 1): the multifidus muscle, interspinal muscles, the longissimus muscle (pars lumborum and pars thoracis) and the iliocostalis muscle (pars lumborum and pars thoracis). 

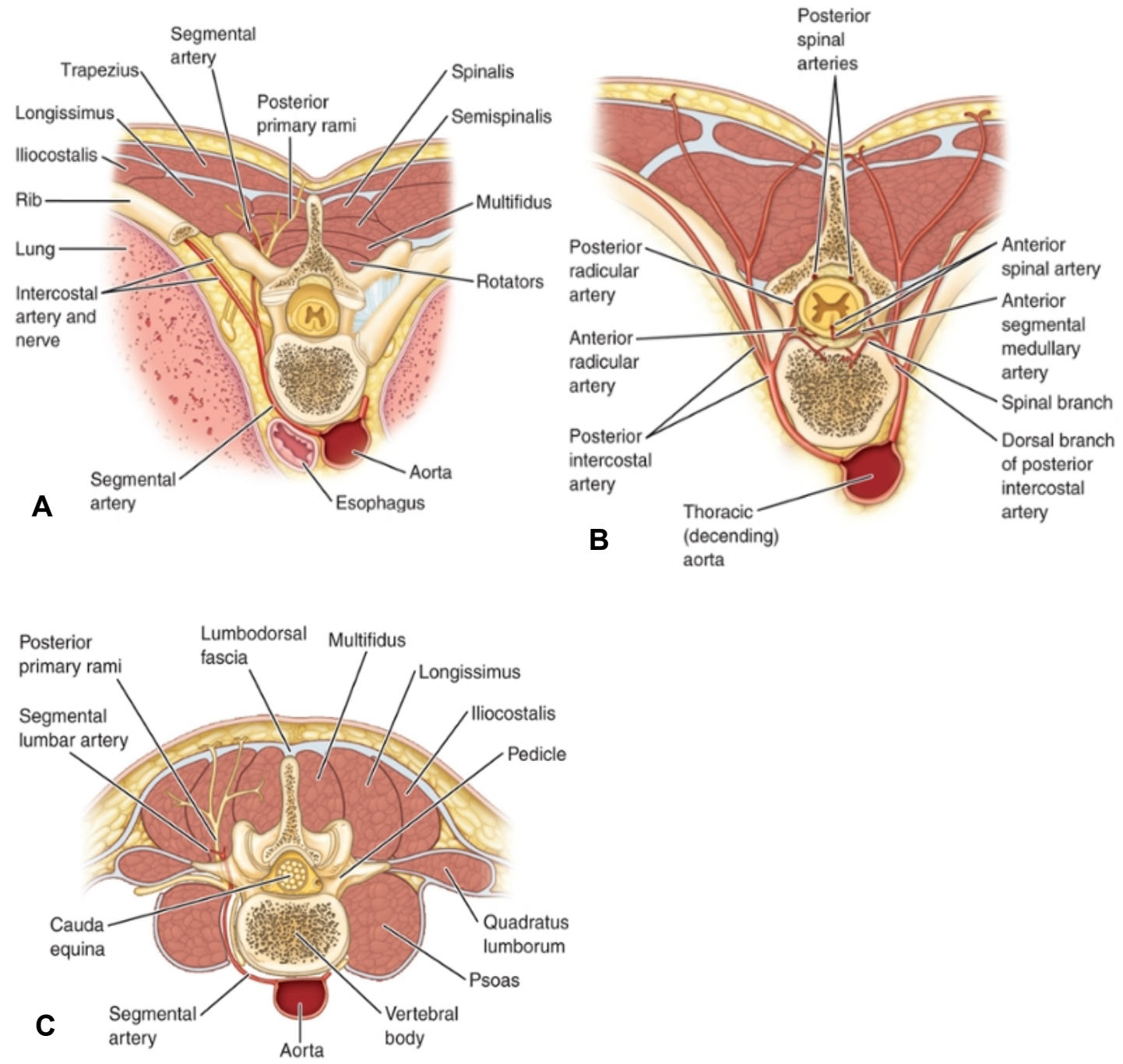

Figure 1: Thoracic, thoracolumbar and lumbar cross-sectional illustrations of the spinal column, with neighboring structures (15).

\section{Mechanical Concepts and Biomechanical Application}

Concepts drawn from the field of mechanics have been applied to the human in-vivo situation in order to allow a better understanding of spinal motion and loading. A few biomechanical terms are explained below that are essential for biomechanical testing and analysis: 
- The mass of an object is the scalar quantity of matter contained in that body. The unit is the kilogram $(\mathrm{kg})$.

- The weight of an object is given by its mass multiplied by its acceleration due to gravity (according to Newton's second law of motion: $f=m \times g)$.

- Force is a vector quantity that has a magnitude and acts on a body by deformation or movement. The unit is the newton $(\mathrm{N})$, with $9.81 \mathrm{~N}$ being approximately equal to $1 \mathrm{~kg}$. Forces may be compressive, tensile, or shear. Forces can be represented by components and can be added up to construct a resultant.

- The intensity of loading is called stress. Stress is equal to the force applied, divided by the area it acts on. The unit is the megapascal (MPa), with $1 \mathrm{MPa}=1 \mathrm{~N} / \mathrm{mm}^{2}$. Hydrostatic pressure is the intensity of loading within a fluid. In contrast to stress, which applies to solids, pressure refers to fluids. The unit is also the megapascal (MPa).

- Displacement is a vector quantity and describes the location of two points relative to each other. The unit is the meter $(\mathrm{m})$.

- Velocity is the rate of change of displacement with time. It is also a vector quantity, with the magnitude speed $(\mathrm{m} / \mathrm{s})$. Acceleration in turn is the rate of change of velocity over time and is also a vector quantity. The unit is $\mathrm{m} / \mathrm{s}^{2}$. 
- The amount of deformation of an object when a force is applied to it is called strain and is the relation of change in length to original length. It can be expressed as a fraction or percentage.

- The bending effect of the force that is applied to an object is the bending moment and is the size of force (in newtons) multiplied by the lever arm (in meters) relative to the center of rotation. The unit is newton meters $(\mathrm{Nm})$. The effect that occurs when a body is twisted and rather than being bent by a force is called torque (Figure 2).

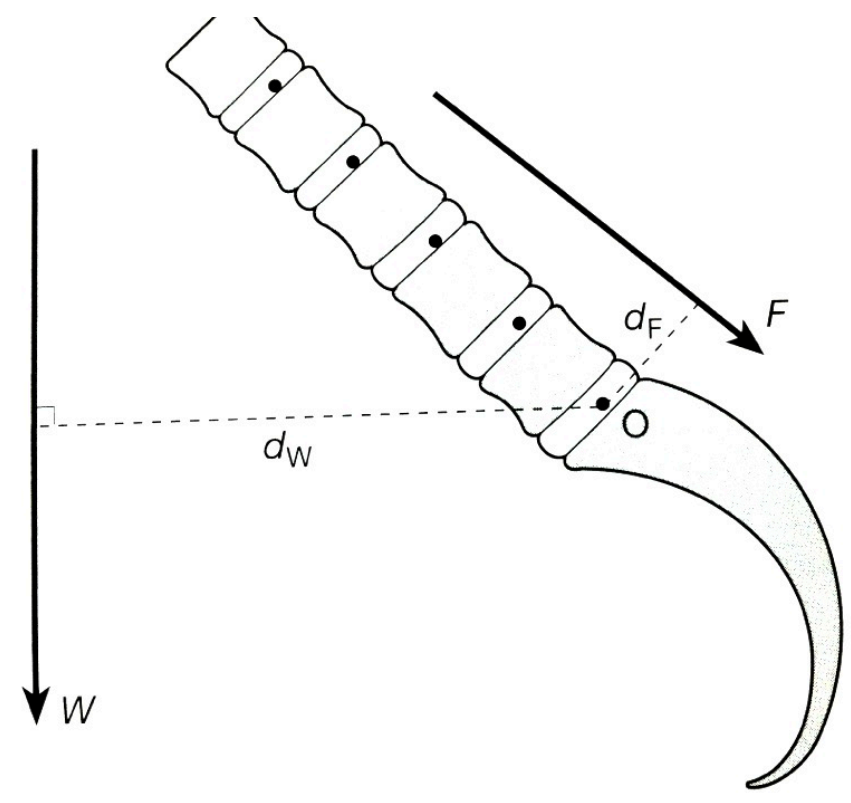

Figure 2: In this example, the body weight $\mathrm{W}$ exerts a flexor moment of $\mathrm{W} \times \mathrm{dW}$ around the center of rotation "O" in the middle of the L5/S1 disc space. No movement is possible if this is balanced by the extensor moment $\mathrm{F} \times \mathrm{dF}$ generated by the back muscles (14). 
- The stiffness of an object is its ability to resist being deformed by a force. Stiffness is measured using the deforming force divided by the deformation it causes $(\mathrm{N} / \mathrm{mm})$. Some biological tissues show increased stiffness with increasing loads, which is therefore called nonlinear. In this case, typical force-deformation graphs can be obtained. In this context, strength is the force at which an object is damaged. On a force-deformation graph, the damage is the first decline in stiffness and the point on the graph at which it happens is called the elastic limit. Beyond the elastic limit, there is irreversible plastic deformation. Ultimate failure occurs when the stiffness falls to zero (Figure 3). 


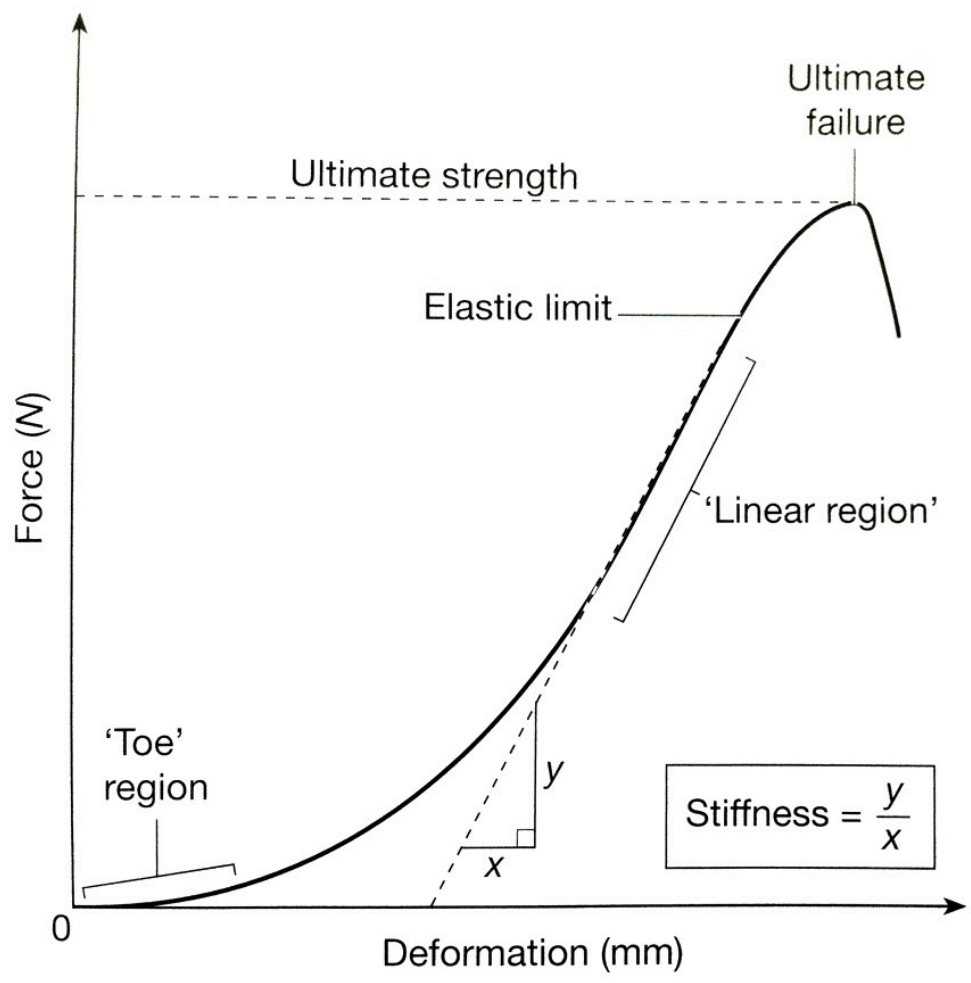

Figure 3: An example of a force-deformation graph in biological tissue (14). "Toe region": deformation increases rapidly with increasing force, indicating that the stiffness of the specimen is low. "Linear region": the stiffness is approximately constant at higher loads. "Elastic limit": the stiffness begins to decline, indicating initial damage to the specimen. "Ultimate failure": stiffness falls to zero. The force at this point is the "strength" of the specimen.

The terms above have been adapted from Adams et al. (14)

\section{Mechanical Properties of the Thoracolumbar Spine}

Even more than the vertebral bodies, ligaments and discs themselves, the curvature of the spine allows it to absorb loads. Energy derived from the upright position, walking, or movement in general can be transferred to tendons of the trunk muscles $(6,14,16)$. 
Spinal loading behavior can be related mechanically to the anatomical structures of the different parts of the spine. In the thoracic spine, the closely associated chest wall restricts most motion, particularly in patients older than the third to fourth decade of life. Depending on chest flexibility, the orientation of the facet joints leads to moderate flexion/extension and low lateral bending. Rotation is highly restricted. Kyphosis in the upper thoracic area shifts the loads that are acting more posteriorly. This results in greater demands on the posterior tension bending system. In the mid-thoracic and junctional region of the thoracolumbar spine (T11-L2), the curvature is aligned almost upright with slightly greater loads acting on the anterior column. The change in rigidity between the thoracic part and the highly flexible parts of the lumbar spine results in a large number of cases of acceleration trauma in this area of the spine (17). The lumbar spine, with its lordotic segmental orientation, distributes $80 \%$ of loads to the anterior parts. The structure and orientation of the facet joints allows the lumbar spine to reach high ROM values. The greatest segmental flexion and rotation movements are found at $L 4 / 5$. Even when the anterior parts of the thoracolumbar column are able to resist most loads, spinal integrity can be lost due to failure of tension bending in the posterior parts.

The examples most widely used to explain load-sharing behavior in the spinal column are the two-column model (anterior and posterior column) described by Whitesides and the three-column model (anterior, middle and posterior) proposed by Denis $(18,19)$. These models involve various load distributions, depending on location in the spine and body posture in healthy individuals. Increasing degeneration of spinal structures influences both spinal loading 
behavior (20) and also deformation by fracture. The development of spinal column defects also inevitably has a significant impact on spinal stability, so that treatment to provide adequate stabilization and research related to such treatment are necessary.

\section{Pathological Spinal Column Defects}

In clinical practice, damage to various parts of the spinal column is most commonly due to traumatic or pathological fractures. Pathological fractures can be classified pathogenetically into osteoporotic (21) and tumor-derived $(22,23)$ structural breakdown.

In the health-care system, osteoporosis is the leading cause of reduced bone mineral density (BMD) and leads to substantial increases in socioeconomic costs $(24,25)$. In the United States, the estimated lifetime risk of suffering from an osteoporotic fracture in women and men aged 50 is $39.7 \%$ and $13.1 \%$, respectively. In women, the risk of developing an osteoporotic fracture rises exponentially up to $70 \%$ by the age of $80(24,26)$. Postmenopausal osteoporosis is one of the major causes of morbidity and mortality in the elderly in Western countries and is associated with very large numbers of hip, wrist and spinal fractures (24). The European Vertebral Osteoporosis Study (EVOS) (27) and EPOS European Prospective Osteoporosis Study $(28,29)$ reported that there is an exponential increase in the rate of osteoporotic fractures with advancing age, with $8 \%$ of women and $5 \%$ of men aged $50-79$ having a minimum of one vertebral compression fracture (VCF). Half of the osteoporotic fractures occurring in the studies were located in the spinal column. Vertebral fractures occur statistically two decades earlier than in 
other locations and are often the first sign of inadequate bone metabolism. The occurrence of a vertebral fracture increases the risk of suffering further fractures in other spinal regions later by a factor of five. This is clinically associated with higher rates of progressive local and global deformity, with kyphotic angles, and an increasing likelihood of further spinal column breakdown. Pathogenetically, the loss of trabecular bone weakens the characteristic bone strands (Figure 4) that give the vertebral body the necessary strength to resist anterior loading (30).
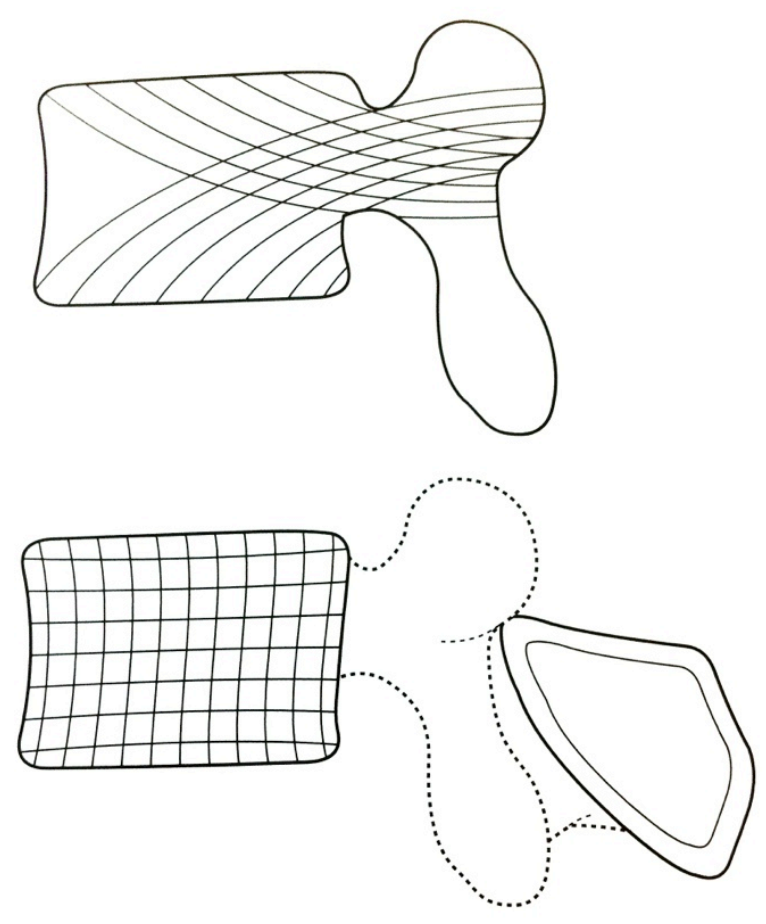

Figure 4: Orientation of trabeculae in different sagittal sections. Trabeculae from the pedicles reinforce the vertebral endplates (above). Trabeculae in the midsagittal plane are orientated more symmetrically (below). Adapted from Adams et al. (14).

The spinal changes caused by osteoporosis can be divided into those with segmental and global pathologies. At the segmental level, degeneration of the 
adjacent discs (1) appears to play a major role: structural disc breakdown leads to a redistribution of the forces that are acting, resulting in greater anterior segmental loading (16). Vertebral body stress shielding is followed by a localized reduction in bone marrow density. Particularly in spinal flexion, unloading of the neural arch occurs and the compressive forces applied are concentrated onto the anterior bone (14). In the process, the rarefied bone becomes more likely to collapse during peak loading. With regard to the spinal column as a whole, significant differences in the sagittal vertical axis between healthy individuals and osteoporosis patients have been shown (31). There are significant differences between individuals with balanced spines and patients suffering from osteoporosis who have imbalanced spines. They differ with regard to age, pain intensity on a visual analogue scale (VAS), lumbar/femoral BMD, alignment parameters such as the sacral slope, and pelvic incidence. Patients who present with a vertebral body fracture have significantly less lumbar lordosis, a smaller sacral slope, and a lower pelvic incidence (32). The risk of a vertebral body fracture is significantly associated with a low level of lumbar BMD, lumbar lordosis and pelvic incidence. However, these pathological changes are not limited to the segmental spinal structures. The vicious circle of progressive anterior load shifting is exacerbated by deranged activity in the trunk muscles. Firstly, degenerative processes in the central nervous system influence the activation of the stabilizing muscle system - e.g., camptocormia as an extreme variant in patients with Parkinson's disease. Secondly, continuous kyphotic deformation results in modification of trunk muscle activity at the muscular level, due to the feedback mechanism for correcting the increased deformity $(33,34)$. This 
leads to greater contraction forces, which have been observed in older patients, patients with greater thoracic kyphosis, and patients with preexisting fractures.

In the upright standing position, the main load on the spinal column is the body mass located above the spinal segments. However, depending on spinal localization, the loads may act on the spinal structures to different extents. In the thoracolumbar spine, $80 \%$ of the incoming load is absorbed anteriorly, while $20 \%$ percent acts on the posterior parts. When there is anterior insufficiency, the loading shifts anteriorly (16). This is associated with compensatory mechanisms - e.g., hyperlordotic positioning of adjacent segments or global hyperlordosis of other mobile parts of the lower vertebral column (35). Without adequate treatment, this leads to progressive deformity and loss of sagittal balance (36). 

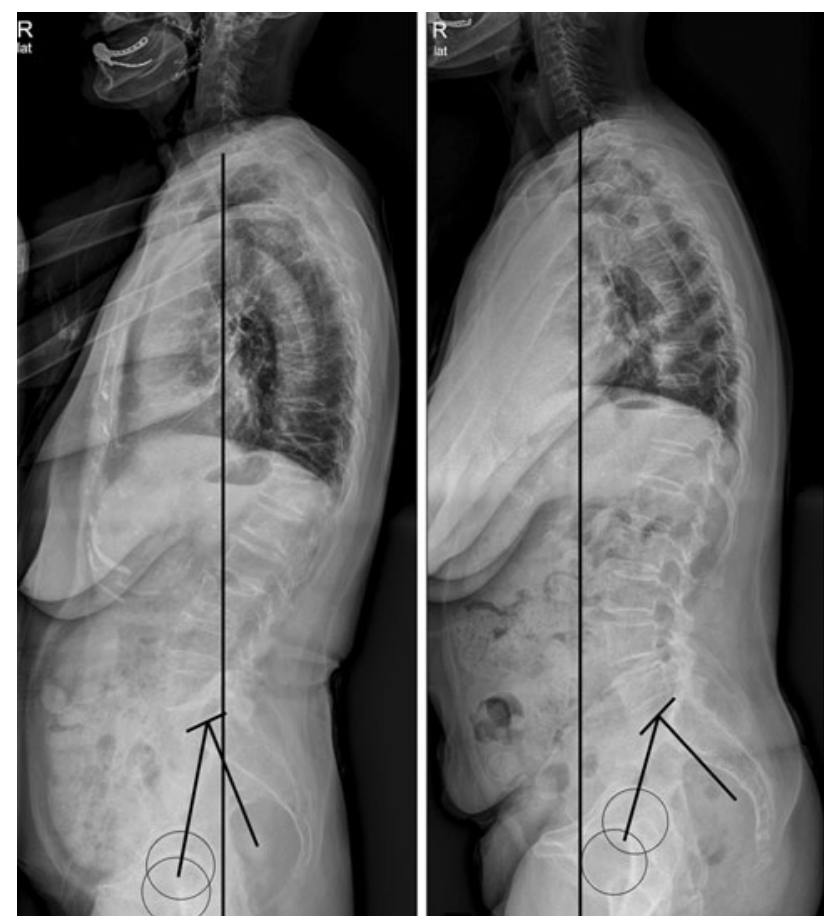

Figure 5: The complete lateral spine in a healthy control individual (left) and in a patient suffering from osteoporosis (right), showing sagittal balance (left) side and an imbalanced alignment (right) (31).

Osteoporotic fractures develop over a period of weeks or sometimes months, and the sudden onset of pain is only one step in the pathogenesis until the progression stops. Continuous micro-motion triggers breakdown and subsidence $(21,30)$. Three different types of fracture patterns associated with specific pathogenetic conditions have been described (37). The most common type, wedge fracture, is based on the anterior stress shielding mentioned above, with unloading of the posterior column during flexional loading. Biconcave fractures result from continuous microfracturing, typically associated with a low grade of degeneration of the intervertebral disc adjacent to the index vertebra. In contrast, the compression fracture type shows advanced degeneration of adjacent discs. During sudden compressive 
loading in slight flexion, the anterior and posterior cortices of the vertebrae collapse (37).

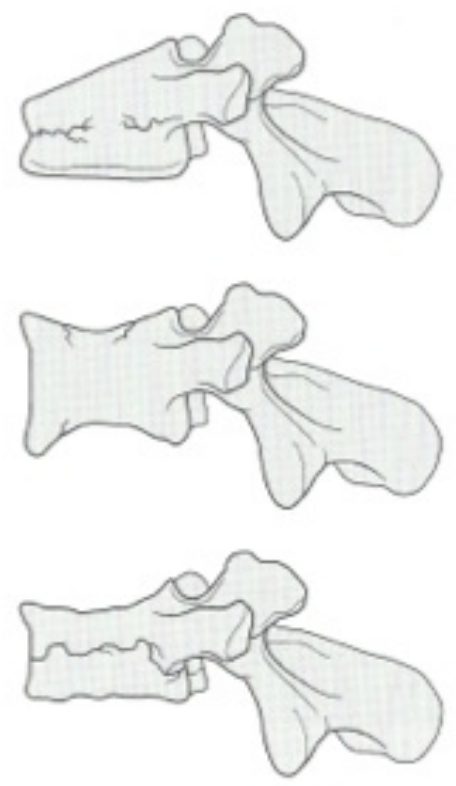

Figure 6: The three different patterns of osteoporotic fracture of the vertebral body associated with specific pathogenetic conditions. From top to bottom: wedge fracture, biconcave fracture, vertebral body collapse (37).

This becomes clinically apparent in pain due to periosteal nerve fiber irritation, which only stops when there is fracture healing or when the stage of vertebra plana develops (38). During the acute phase of fracture pain and inflammation, mediators are released that cause local pain, while the trunk muscles are activated due to reflex pathways (38). As a side effect, the intervertebral discs and facet joints also react based on mal-loading, leading to local pain and additional muscle activation (33). Patients with continuous pain due to pathological spinal conditions are at a high risk of developing chronic back pain syndromes $(37,39)$. 
Although a systematic description of traumatic lesions in the vertebral body is available (the AO spine classification) (17), pathological fractures are difficult to classify. Various attempts have been made to systematically investigate the patterns of osteoporotic fractures (e.g., the OF classification proposed by the Spine Study Group of the German Society of Orthopaedic and Trauma Surgery, DGOU) and tumor-derived fractures (4, 40). Treatment algorithms have been established relative to the extent of the vertebral body defect and resulting malalignment, involvement of the discs and spinal canal, and the patients' general health status. Adequate surgical strategies are also necessary in view of the pain, impaired mobility and reduced quality of life for the patients $(41,42)$.

In a constantly growing and aging population, the numbers of pathological vertebral compression fractures (VCFs) are continuing to increase. The majority of neoplasms that cause VCFs requiring surgical intervention are secondary lesions $(43,44)$. Depending on their biological behavior, different cancer entities have varying tendencies to cause spinal metastases (renal cell cancer $30 \%$, lung cancer $45 \%$, breast cancer $70 \%$, prostate cancers $90 \%$ ). The National Cancer Institute in the United States (www.cancer.gov/statistics) has recorded a $500 \%$ increase in the prevalence of spine metastases over the last 25 years. In addition to pain as a nonspecific symptom, serious complications include neurological deficits due to direct spinal cord or nerve root involvement (45) and the risk of mechanical instability (46-48) that has been shown to be a factor directly influencing the patients' quality of life (49). The aim with all therapeutic procedures should therefore be rapid and adequate stabilization of the thoracolumbar area involved (50). 


\section{Stabilization of the Thoracolumbar Spine}

The diagnosis and treatment of spinal diseases was already described in the earliest period of the history of the medicine. In the Hippocratic Corpus manuscripts attributed to Hippocrates (c. $460-$ c. $377 \mathrm{BC})$ - attention is drawn to the importance of pathological changes in the spine and maneuvers for axial correction of such changes are described. During the Renaissance, Ambroise Pare (1510-1590) introduced the first supporting jackets used in the treatment of deformities (51). The first surgical treatments involved fusion operations. In New York in the early 20th century, Albee and Hibbs carried out the first spondylodesis for patients suffering from Pott's disease, using different autologous osseous grafts (52-54). In the 1930s, the first metal implants were used for internal fixation to improve stability. These developments accelerated in the second half of the 20th century with surgeons such as Harrington, Luque, Judet and Larrick, who introduced new types of implant (55). Further progress in improving reconstructive stability was achieved by Raymond Roy-Camille, who placed the first transpedicular screws in $1963(56,57)$. The devices known as pedicle screws are still the "gold standard" for posterior fixation. Various stabilization systems based on pedicle screws have been developed in recent years for patients with degenerative instability in order to guide movement within predefined limits.

The introduction of a standardized anterior access route to the thoracic spine, thoracolumbar junction and lumbar spine (58) made it possible to carry out circumferential fusions of all three columns in the Denis model $(19,59)$. Reconstructions of extensive defects in the thoracolumbar spine can now be managed using a combination of vertebral body replacement systems (VBR), 
anterior or anterolateral plating systems and posterior pedicle screw and rod systems (60).

Various publications described a negative influence on secure implant anchorage due to reduced vertebral BMD and an impaired implant-bone interface (61-67). There is therefore an urgent need for effective alternatives to increase the stability of the constructs and support bone healing. Angular stable implants, which have already successfully been shown to enhance stability in fracture fixation of the extremities, were therefore also developed for spinal surgery (68). Osteoporosis is defined as rarefaction of trabecular bone. In patients in whom conservative treatment fails, surgical fracture therapy is challenging. Implant anchorage mainly depends on the contact area between the alloplastic material and the bone structures. A reduced load-bearing surface therefore leads to increasing peak loads in the rarefied bone-implant contact areas, with an increased risk of local interface loosening. The resulting loads have to be redistributed to other areas, with progressive loosening, which may result in complete implant failure (69).

\section{Vertebral Body Augmentation}

In the mid-1980s, Deramond et al. and Galibert et al. introduced a technique of bone cement augmentation for pathological vertebral fractures $(70,71)$. Cement augmentation was the first method described and successfully applied for the treatment of osteoporosis-derived and tumor-associated pathological fractures, and it led to rapid pain relief and early mobilization of the patients $(3,30,72-75)$. While the technique achieved good clinical results in relation to these aspects, fracture reduction is characteristically only 
possible using closed reduction maneuvers prior to surgery. Alternatives were therefore introduced in order to further secure reductions and regain stability $(76,77)(78)$. New techniques such as kyphoplasty and lordoplasty $(30,79$, 80) were introduced to improve the clinical outcome, safety and benefits of surgical procedures. As minimally invasive treatment options, all of these procedures achieve partial reduction and stability to a certain extent, along with a short rehabilitation period. Placing bone cement in vertebral bodies is also associated with well-described limitations and complications, including as leakage, embolism and an increased risk of VCF in the adjacent vertebrae $(81,82)$. Leakage of the cement into neighboring structures can affect the spinal canal, veins, and intervertebral discs. Bone cement thrombosis in paraspinal vessels and lung embolism are also known risks $(77,83)$.

However, cement augmentation techniques for pathological thoracolumbar fractures are nowadays clinically well-established methods that allow rapid pain relief, preservation of vertebral body height, and early mobilization of the patient $(74,84)$. Since the time when the classic vertebroplasty procedure was first introduced, various attempts have been made to achieve more than simply preventing further fracture subsidence by stabilizing the collapsed bone. The focus of interest has shifted to restoring the individual physiologic segmental and general spinal alignment, and this appears to be crucial for protecting the adjacent segments by reducing the risk of additional fracturing and secondary kyphotic deformities. Although the morphological appearance after pathological vertebral body fractures is different from that with traumatic structural breakdown, the pathophysiological results are similar (with posttraumatic kyphosis and associated comorbidities, for example). From the 
biomechanical point of view, therefore, the grade of fracture reduction appears to be just as important as in nonosteoporotic fractures. The kyphosis that occurs after treatment alters the distribution of forces acting on the pathologically impaired vertebral body, particularly in the thoracolumbar spine (35). An anterior shift in the axis of rotation is accompanied by nonphysiological loading of the cortical and trabecular bone. In a porous microstructure, hyperproportional loading leads more quickly to local load peaks, followed by structural breakdown and progressive failure. As a result, the surrounding structures have to compensate for additionally occurring forces. This is followed by a greater likelihood of fracturing, leading to a chain reaction of local or disseminated collapse (85). In comparison with simple vertebroplasty, kyphoplasty provides a better solution to the clinical problem of insufficient reduction of segmental deformities following pathologic fractures (86), with lower cement leakage rates being reported (87). Although it provides improved reduction, however, the kyphoplasty implantation technique results in differences between the kyphosis angle achieved during maximum balloon inflation and the final angle achieved after cement application. This technique-related loss of reduction is known as the "deflation effect" and can result in intrasegmental kyphosis and overall alignment failure. Cement augmentation systems have been developed in order to minimize the deflation effect while at the same time enhancing stability and bone anchorage $(88,89)$. Vertebral body stenting (88) was introduced in order to maintain height restoration after deflation of the balloon, with the aim of achieving better alignment restoration (Figure 7). The extent to which different combinations of materials may be able to influence the biomechanical effects 
of balloon deflation on the reduction result and preserve the reduction is as yet unclear.

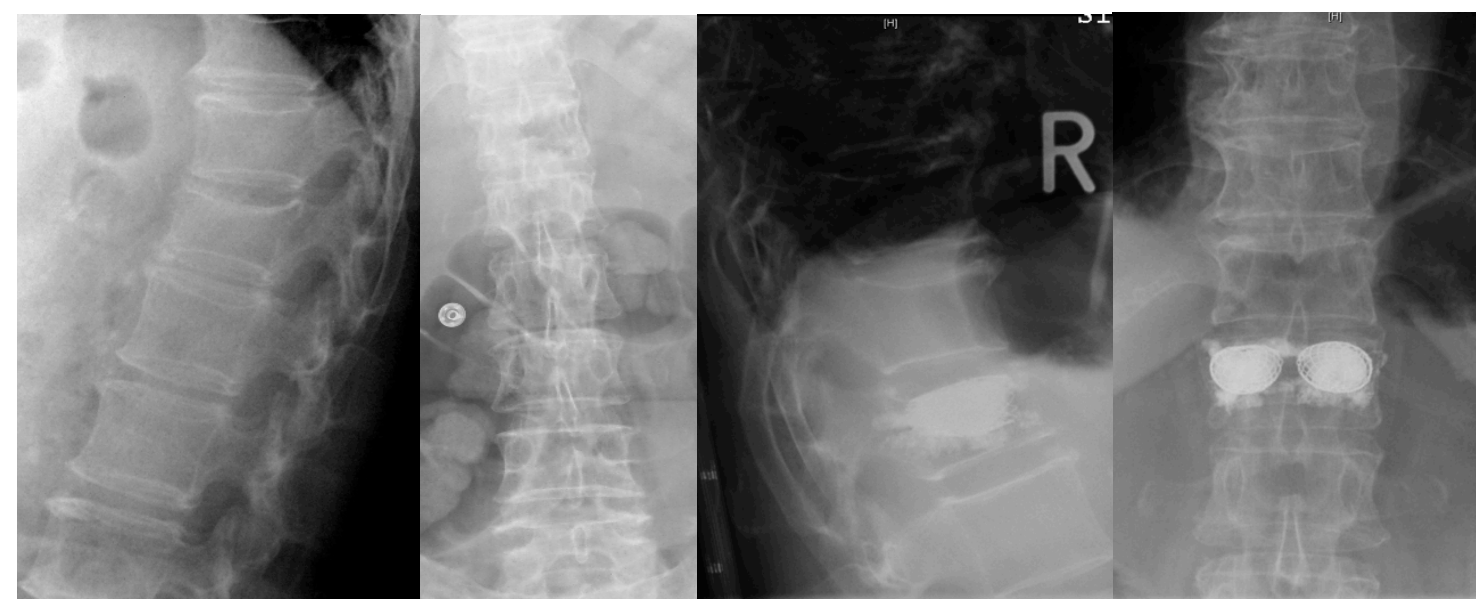

Figure 7: A 62-year-old woman suffering from a T12 fracture (lateral and anteroposterior radiographs, left side) in osteoporotic bone. Treatment with vertebral body stenting was carried out (lateral and anteroposterior radiographs, right side).

Kyphoplasty/vertebral body stenting techniques are performed with patients under general or local anesthesia lying in a prone position on a carbon surgical table. Closed reduction prior to surgery is possible in this set-up. Two fluoroscopes are used to determine the location of the skin incisions in projection relative to both pedicles (Figure 8). 


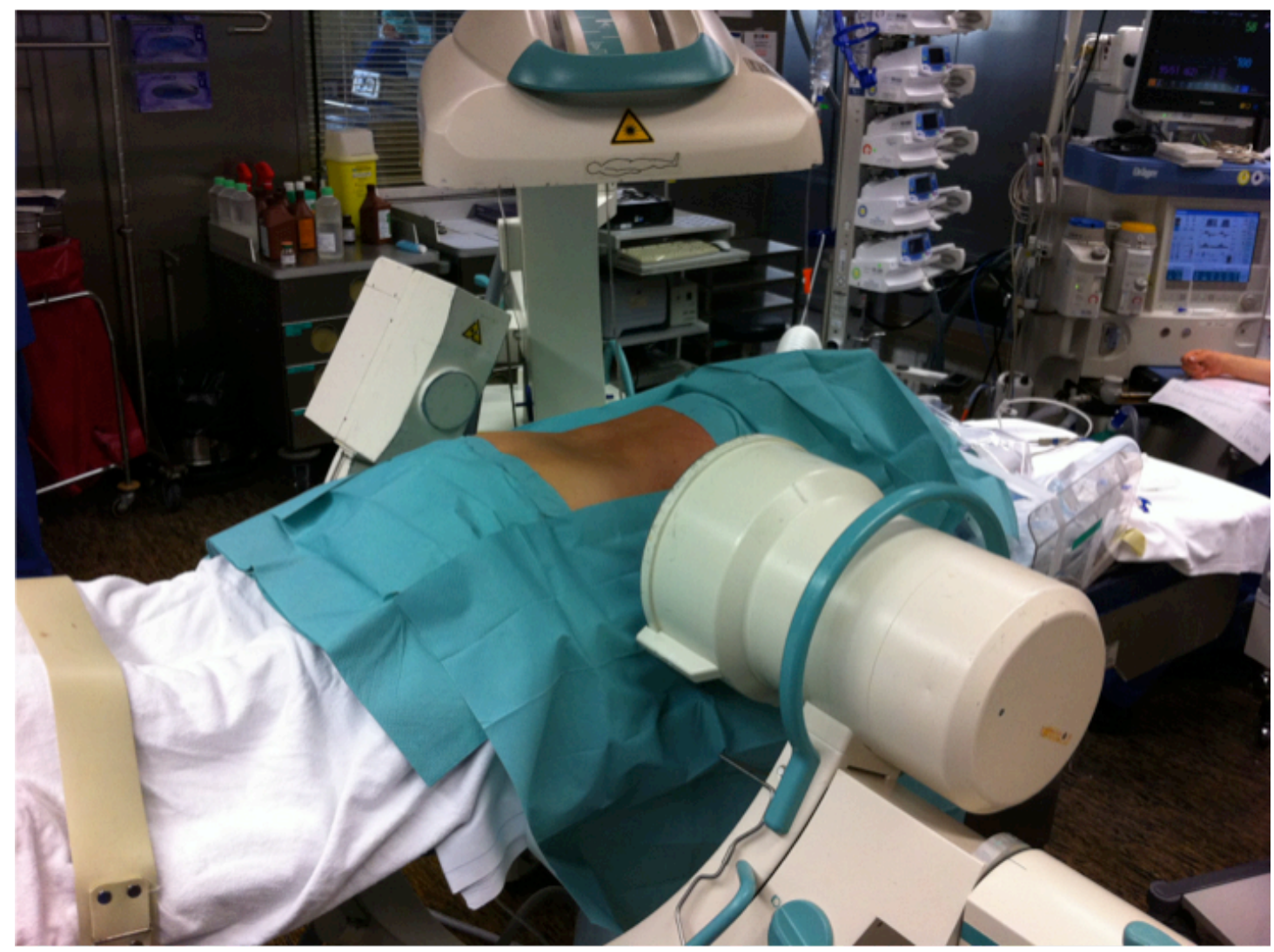

Figure 8: The intraoperative set-up, with a patient lying in prone position on a carbon table and two fluoroscopes for simultaneous lateral and anteroposterior $\mathrm{x}$-ray viewing.

The location of the skin incision at the thoracolumbar spine for the transpedicular approach is $1-2 \mathrm{~cm}$ lateral and up to $1 \mathrm{~cm}$ cranial to the center of the pedicle. Following blunt dissection through the subcutaneous layers, the fascia is opened. The extensor muscles are evenly dissected, and the area between the lateral aspect of the pedicles and the transverse process is reached. The transpedicular path is created using guide wires or trocars as access instruments. To avoid damage to the spinal canal, the tips of the access instruments must not pass the midline wall on the anteroposterior $\mathrm{x}$ ray view until they have passed the posterior wall in the lateral view (Figure 9). 


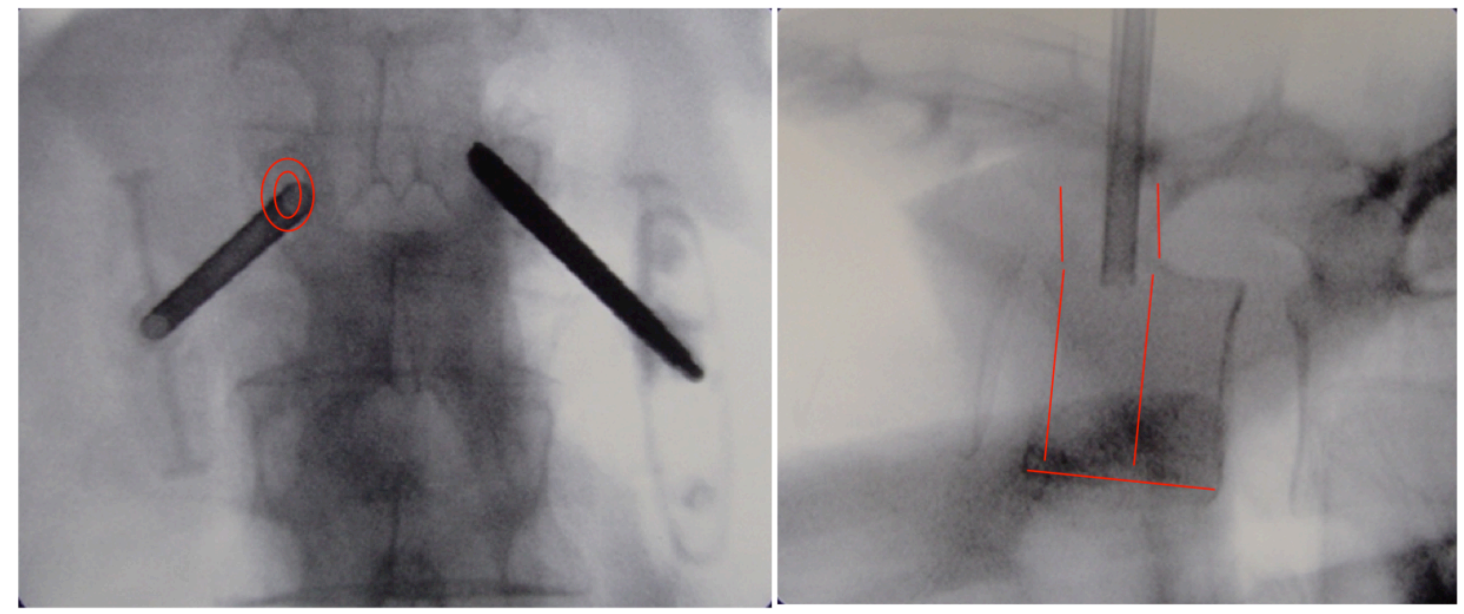

Figure 9: Intraoperative fluoroscopic evaluation of the transpedicular path into the vertebral body, with anatomic boundaries. Anteroposterior view of the pedicle (red circles); lateral view with pedicle borders, area below the fractured endplate and anterior wall (author's own archive).

When advancing the access path into the vertebral body, it is essential to avoid exaggerating the anterior cortical wall and harming the anterior vascular structures. Under continuous radiographic control, proper access canals can be created by drills and plungers to allow good balloon positioning afterwards. At spinal levels in which there are small pedicle diameters (upper thoracic spine), a parapedicular approach can be used to obtain access to the vertebral body. A balloon stent (Figure 10) is selected before the operation by measuring the dimensions of the fractured vertebral body and the extent of the planned reduction. The balloons are connected with tubes to a syringe with a manometer. This application system allows filling to be carried out against greater resistance and makes it possible to create a cavity and reduce fractures. In the vertebral body stenting (VBS) system, a balloon is combined with a mesh stent that secures the cavity that has been created after deflation. 



Figure 10: An inflated kyphoplasty balloon (left; Medtronic Inc., Minneapolis, Minnesota, USA) and an expanded vertebral body stent (right; DePuySynthes Ltd., Zuchwil, Switzerland). Both systems are available in different sizes adapted to the different spinal levels.

Balloons/stents corresponding to the size of the vertebral body are placed under fluoroscopic guidance, to ensure that they are positioned completely inside the vertebra with the maximum reduction benefit. An inflation system filled with a mixture of contrast medium and saline solution is connected to the balloon catheters following evacuation of the system. Contrast can be carefully delivered to the balloons to expand them, and resistance is monitored with a manometer (Figure 11). Reduction can be checked by the decline in pressure achieved following each inflation step. When the pressure measured remains constant during inflation, the maximum reduction without further disturbance of the integrity of the vertebra has been reached. 


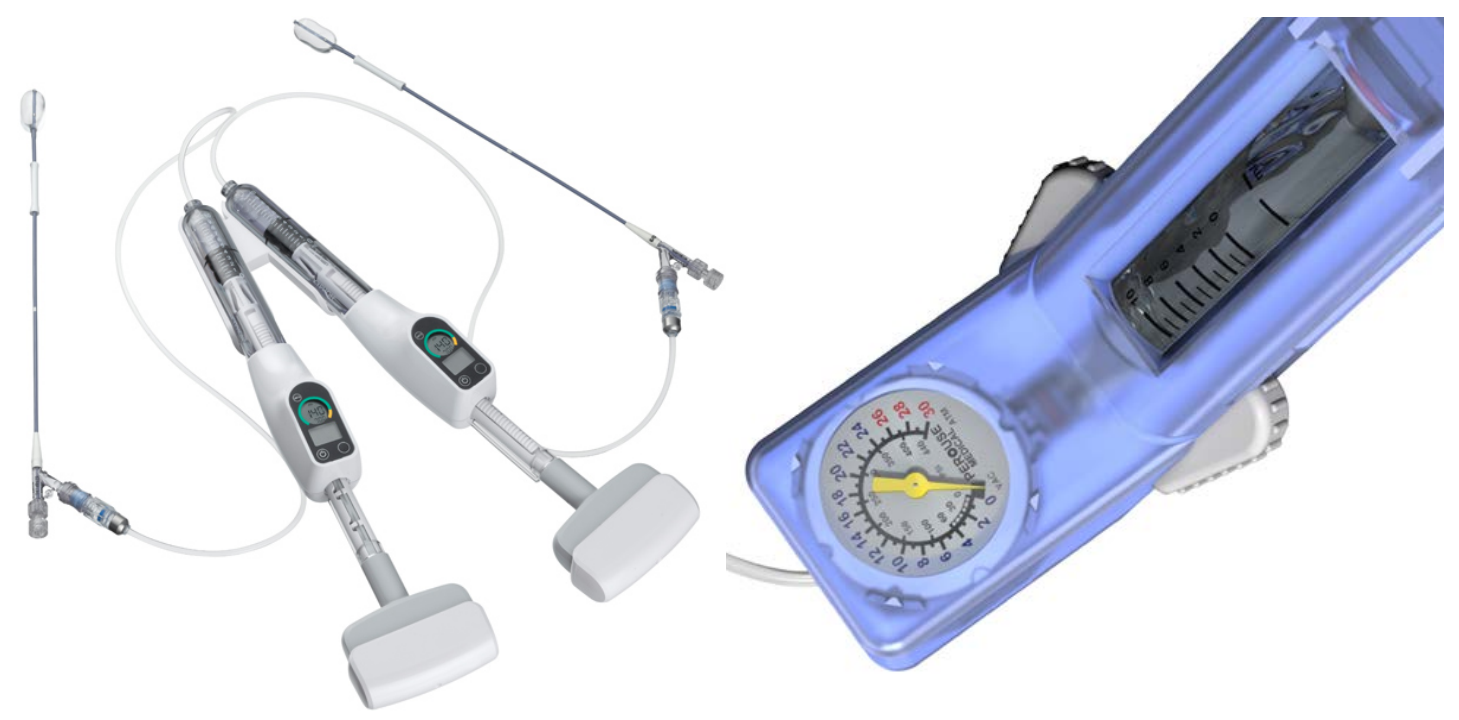

Figure 11: Kyphoplasty (left) and vertebral body stenting (right) inflation systems. The manometer displays the measured pressure actually acting in the system in psi (pounds per square inch) and atm (atmospheres).

Continuous radiographic checking is necessary to avoid overexpansion or breakout of the vertebral cortical walls. Usually, both sides of the vertebral body undergo these steps. If the degree of reduction needed has been reached, careful deflation is possible using the same inflation system. The bone cement volume can be estimated from the volume of the balloon inflation medium needed for expansion. The cement is injected by a delivery system consisting of cannulas and syringes or plungers until it infiltrates the surrounding cancellous bone around the previously created cavity. Once the cement has cured, all of the cannulas are removed and the final anteroposterior and lateral radiographic checks are carried out. 


\section{Measuring Primary and Secondary Stability in Biomechanical In-Vitro Experiments}

With the continuing advances in spinal surgery that have been made in recent decades, in parallel with the introduction of new implants, an urgent need has emerged for a standardized method of in-vitro simulation in laboratory conditions. Biomechanical models, particularly in the thoracolumbar spine, can provide the basis for answering more specific clinical questions and have been the topic of numerous pioneering publications $(9,12,14,19,59,90-94)$.

As shown in Figure 3, the loading of biological tissues is characterized by the action of a force and a deformation response. When the deforming force is released, the specimen returns to its original shape and the strain energy is released. In a perfectly elastic object, the original shape is regained precisely and the complete strain energy is recovered. Biological specimens are characterized by a certain amount of inelastic deformation, in which some of the stored strain energy is lost as heat and the original shape is not regained immediately. The strain energy that is not recovered is referred to as hysteresis energy. Spine simulators were developed to make it possible to induce physiological, deforming loads on all three main planes of motion (flexion/extension, lateral bending, axial rotation) in spinal specimens (Figures 12 and 13). 


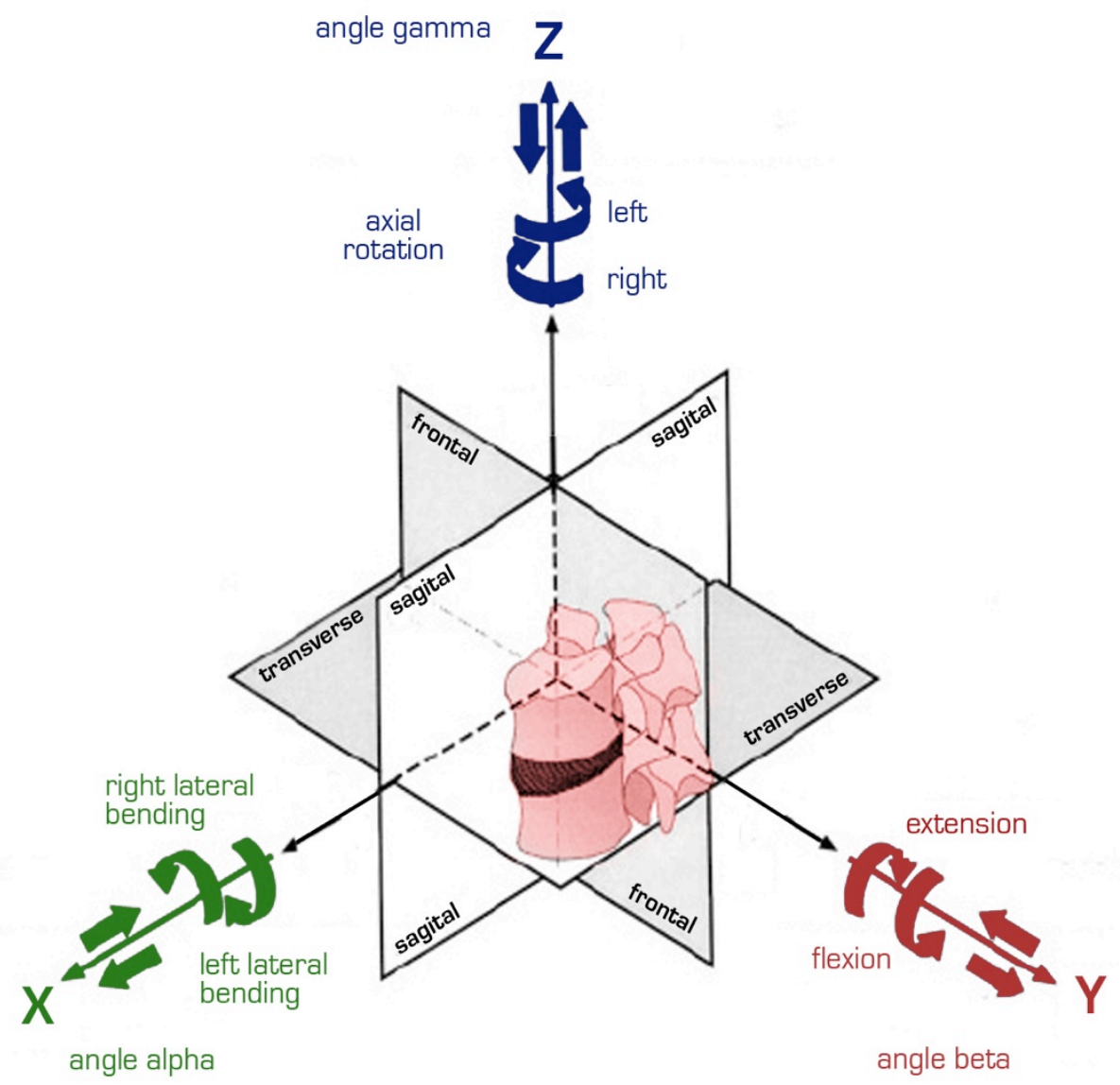

Figure 12: The international definition of the coordinate axes in the spine, showing possible translations and rotations along the coordinate axes according to Wilke et al. (12). 


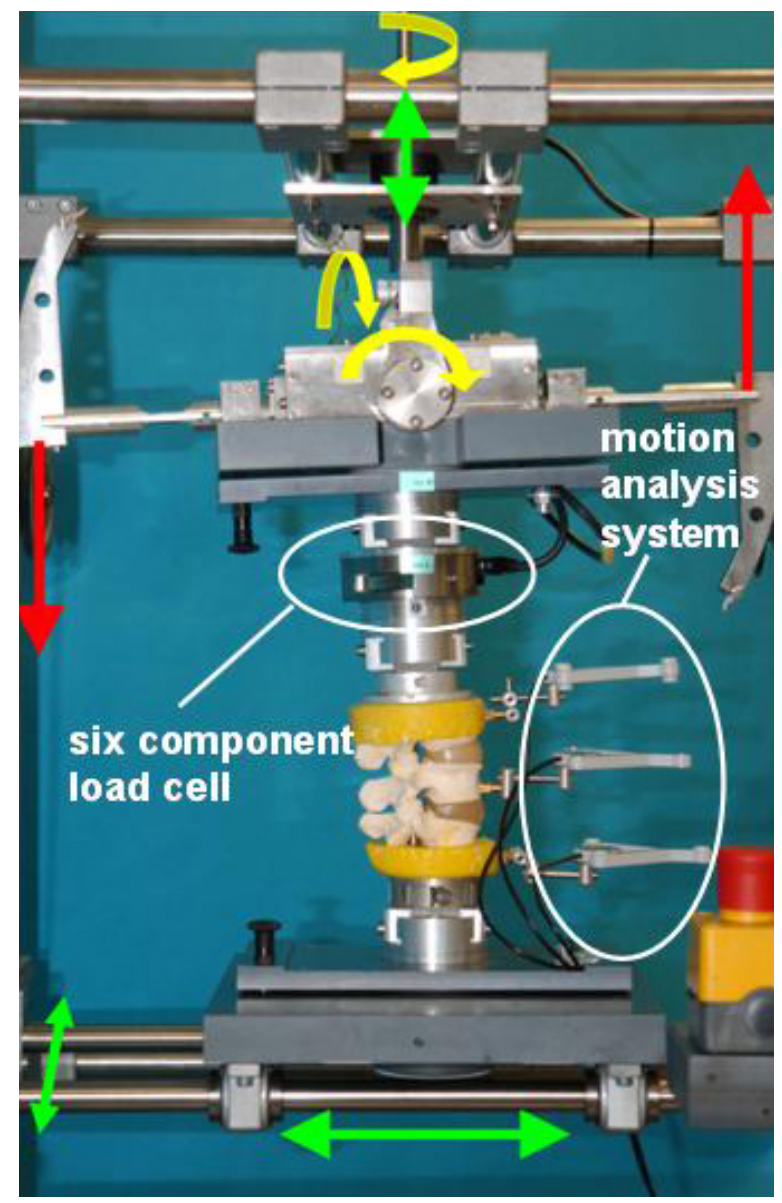

Figure 13: A spine simulator with six degrees of freedom for in-vitro biomechanical testing. The green arrows indicate the possible axial translations, the yellow arrows show possible axial rotations and the red arrows show the direction of load application with tension cables connected to a computer-controlled stepper motor.

Matching the mechanical conditions in the thoracolumbar spine, pure moments are used in the simulator while distorting sources of bending moments are excluded. The force-deformation graph that results from a spine tester loading sequence is typically displayed as a hysteresis curve. This can be used as a basis for measuring stiffness or primary stability. The studies by Wilke et al. made a decisive contribution to the standardization of the constructions and set-ups used for spinal testing. Standardized testing methods made the results obtained comparable $(9,12,90,91)$. 
Secondary stability investigations in material testing machines are used to provide more detailed information about the behavior of specimens during continuous loading. Small forces that act can create microscopic damage that may pass unnoticed in small quantities but can accumulate until failure in large numbers of loading procedures. This fatigue failure can occur after only a few loading cycles if the load applied is more than $60 \%$ of the strength of the structure, or it may require a much larger number of loading cycles if the load is below $30 \%$ (Figure 14).



Figure 14: Fatigue curve, showing the reduction of strength with the number of cyclic loading procedures. The fatigue limit is a threshold in some materials, below which loading will never lead to failure (14).

Secondary loading sequences are typically conducted as load cycles with lower and upper limits. While the loading frequency and number of load cycles remain the same, the upper load limit can be increased until the specimen breaks down (95). 


\section{Purpose of the Study}

The present study addressed the following question: Are there any differences between balloon kyphoplasty (BKP) and vertebral body stenting (VBS) in a biomechanical in-vitro investigation using human specimens in a standardized thoracolumbar fracture model, in relation to:

Changes in the segmental kyphosis angle during fracture reduction, deflation, and cement application?

Spinal flexibility and the effects of a three-step cyclic flexion loading protocol? 


\section{Materials and Methods}

\section{Specimens}

For the purposes of biomechanical testing, 12 fresh frozen human thoracolumbar spine specimens $(6 \times$ T2-L2 and $6 \times$ L3-L5) were harvested from three female and three male donors with an average age at death of 76.3 years (range 63-89 years). The bone mineral density (BMD) of all specimens was measured using preoperative quantitative computed tomography (GE LightSpeed VCT16; GE Healthcare Inc., Waukesha, Wisconsin, USA), including European Forearm Phantom calibration (EFP; QRM Ltd., Möhrendorf, Germany). The mean trabecular bone mineral density was $76.8 \mathrm{mg} / \mathrm{cm}^{3}$ (SD $\left.10.9 \mathrm{mg} / \mathrm{cm}^{3}\right)$. Reference values in the literature for BMD measured using quantitative computed tomography are $96.6 \mathrm{mg} / \mathrm{cm}^{3}$ and $68.6 \mathrm{mg} / \mathrm{cm}^{3}$ for the age groups of 60-69 and 70-79 years, respectively (96). The specimens were evenly distributed among the two treatment groups relative to age, spinal level, and bone mineral density. Specimens in which pathologic changes were noted on the computed tomography scans were excluded from the study.

\section{Preparation of the Specimens}

The specimens were kept vacuum-sealed and frozen at $-20{ }^{\circ} \mathrm{C}$ in double plastic bags until the definite testing date. They were thawed overnight at $6{ }^{\circ} \mathrm{C}$ and prepared at room temperature immediately before testing (97). The supporting soft-tissue structures (e.g., discs, ligaments, capsules) were left untouched, while all muscular tissue was removed. After preparation, the middle vertebral body (L1 or L4) in the test specimen was aligned horizontally 
in a fixation device. The upper part of the cranial ends (T12 or L3) and the lower part of the caudal ends (L2 or L5) of the specimens were embedded in polymethylmethacrylate (PMMA) cement (Technovit 3040; Heraeus Kulzer Ltd., Wehrheim, Germany), leaving the facet joints and discs intact. Flanges were mounted on the upper and lower ends of the PMMA blocks of the specimens. The flanges were rigidly fixed to the frame of the spine tester. Fixation screws for the three-dimensional motion analysis system (Winbiomechanics; Zebris Medical Ltd., Isny, Germany) were mounted to the anterior side of the cranial and caudal PMMA blocks.

\section{Wedge Fracture Creation}

Prior to the reduction and stabilization procedures, the middle vertebra of each prepared specimen was fractured in a standardized set-up. The fracture was created using a custom-made jig in a servohydraulic materials testing machine (MTS 858 MiniBionix II; MTS Systems Corporation, Eden Prairie, Minnesota, USA) (Figure 15). The jig applies an eccentric load in flexion while protecting the posterior wall, and thus makes it possible to create an A1 fracture (according to the AO spine classification) with endplate impaction. The specimens were fractured under displacement control (speed $20 \mathrm{~mm} / \mathrm{min}$ ) and compressed to achieve $50 \%$ of the intact vertebral body height. After fracturing, the displacement was held for $2 \mathrm{~min}$. This technique was developed and applied in preliminary and previous experiments and has been shown to create reproducible fractures $(98,99)$. 



Figure 15: Fracture creation and cyclic loading in the servohydraulic materials testing machine. The loading jig is connected to the testing machine with two ball-and-socket connections. On the dorsal side of the loading jig, the two loading plates are connected to the rods with two hinge joints to ensure loading in flexion.

\section{Fracture Treatment with Augmentation Techniques}

The fractured specimens were treated in accordance with the companies' implantation guidelines. The fractures were treated under fluoroscopic guidance in a custom-made fixture, allowing height to be restored against a bending moment. One end of the specimen was left unconstrained, to allow both axial and angular displacement during reduction and treatment of the vertebral body fracture while a flexural bending moment of approximately $2.5 \mathrm{Nm}$ was applied via an eccentric preload of $55 \mathrm{~N}$. This method not only simulates the load acting on a vertebral column in the prone position, but most 
importantly it effectively balances the spontaneous viscoelastic height restoration of the vertebral body and allows controlled height restoration.

Balloon kyphoplasty $(B K P)$. Using transpedicular trocars, the 15-mL kyphoplasty balloon (Medtronic Inc., Minneapolis, Minnesota, USA) was placed bipedicularly in the cephalad third of the vertebral body. Expanding the balloon created a cavity with an average volume of $4.83 \mathrm{~mL}$ (SD $0.24 \mathrm{~mL}$ ). Following reduction, each of the two cavities was filled with $5 \mathrm{~mL}$ of bone cement (Vertecem V+; DePuySynthes Ltd., Zuchwil, Switzerland). The specimens were left fixed and loaded into the radiography jig with an eccentric preload of $55 \mathrm{Nm}$ until the PMMA cement had cured.

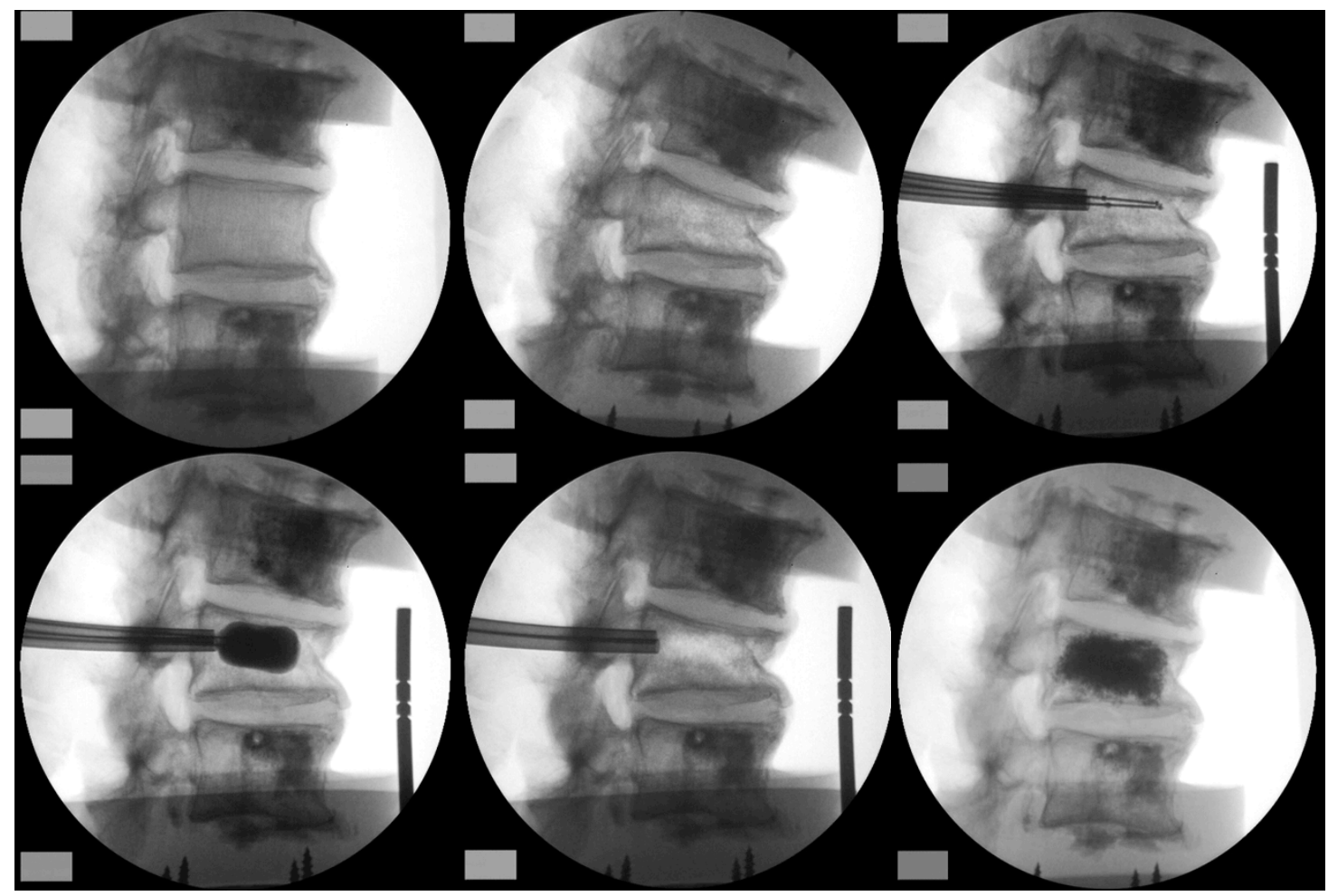

Figure 16: X-ray series of a specimen treated with kyphoplasty (from left to right): 1) intact specimen, 2) following fracture creation, 3) balloon placement, 4) balloon inflation, 5) following balloon deflation and 6) cement augmentation. 
Vertebral body stenting (VBS). Using the same access as described above for the kyphoplasty technique, vertebral body stents (size M, DePuySynthes Ltd., Zuchwil, Switzerland) were inserted into the vertebral body and expanded until it acquired an ellipsoid shape with an average volume of $4.83 \mathrm{~mL}$ (SD $0.37 \mathrm{~mL}$ ). Subsequently, $5 \mathrm{~mL}$ of bone cement was also filled into the remaining cavity until it showed good anchorage to the surrounding bone. The specimens were left fixed and loaded into the radiography jig until the PMMA cement had polymerized.

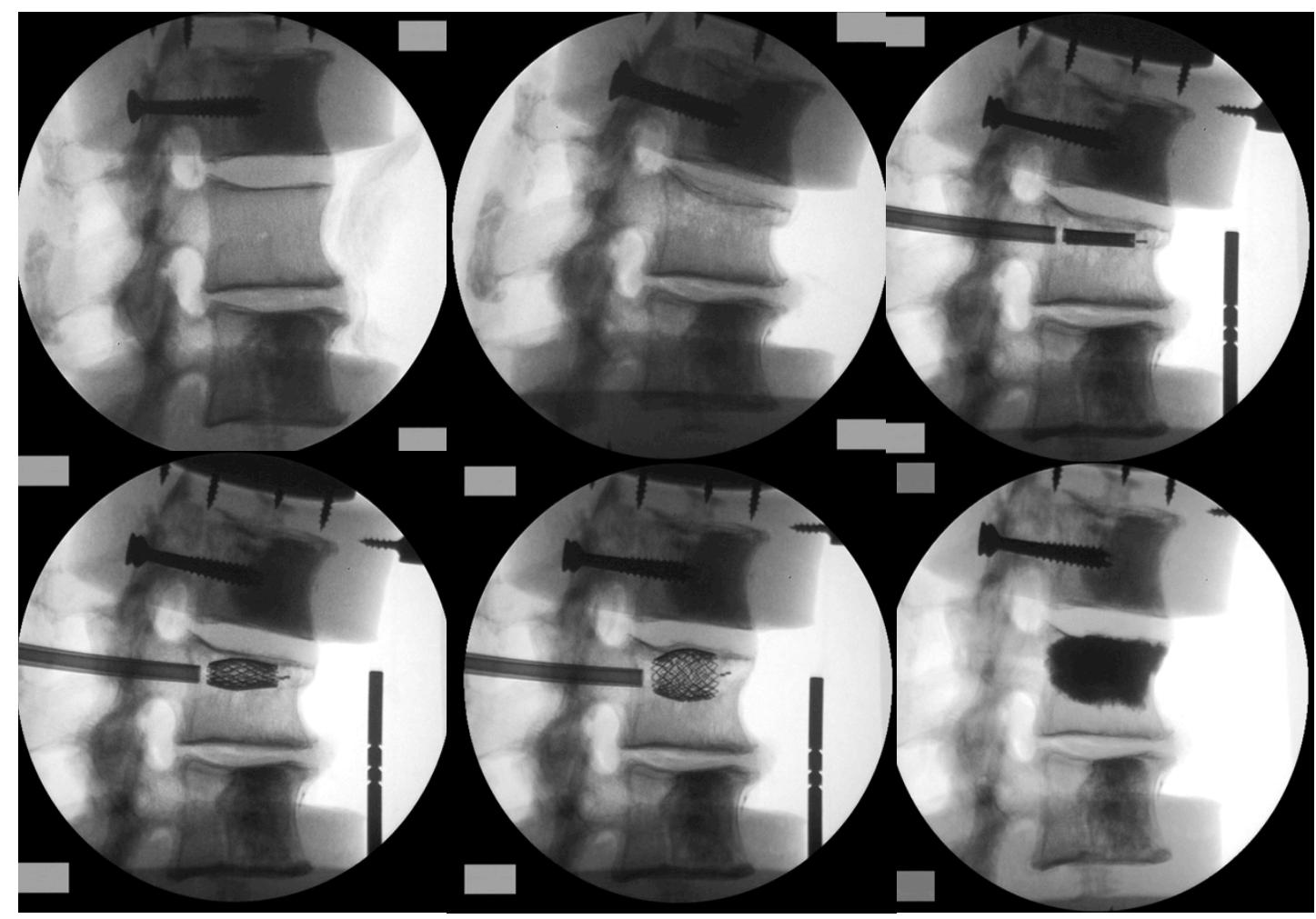

Figure 17: X-ray series of a specimen treated with VBS (from left to right):

1) intact specimen, 2) following fracture creation, 3) stent placement, 4) balloon inflation, 5) following balloon deflation with expanded stent and 6) following cement augmentation. 


\section{Flexibility Testing in a Spine Simulator}

The range of motion in flexion and extension was used to evaluate the stability of the two stabilizing methods being investigated. All flexibility testing of the specimens was carried out in a spine tester that was developed inhouse (WiSi, Figure 18). This set-up is in analogy with the recommendations for testing of spinal implants $(9,90,91,94)$. A square with a double row of tracking bars mounted with ball bearings on a metal frame allows a sliding carriage with the specimen to move with six degrees of freedom. Loads of up to $7.5 \mathrm{Nm}$ were induced at the cephalad part of the specimen by a stepper motor using cable pulling. To avoid overloading, the moments and forces induced at the cranial end of the specimen were recorded using a feedbackcontrolled six-component load cell (FT Delta SI 660-60; Schunk Ltd., Lauffen am Neckar, Germany). During loading of the specimens with pure moments in flexion and extension, two parameters were recorded continuously (Table 1).

The loads at the cephalad end of the specimen were recorded using a sixcomponent load cell placed in line with the specimen.

Intersegmental rotation was measured using an ultrasound-based motion analysis system (Winbiomechanics; Zebris Medical Ltd., Isny, Germany).

Measurements of the range of motion (ROM) during loading included the fractured vertebral body as well as the two adjacent discs. The hysteresis curves of the moment/angle graphs were used to determine the ROM and neutral zone. To allow preconditioning of the specimens and to minimize the viscoelastic effect, only the third load cycle was evaluated and used for further 
analysis and comparison. All flexibility tests were carried out at room temperature. The specimens were kept wet for the duration of testing.

\begin{tabular}{|c|c|c|c|}
\hline Device & Type & Manufacturer & Range \\
\hline Spine tester & WiSi & In house & \\
\hline Six-component load cell & $\begin{array}{l}\text { SI }-660-60 \\
\text { FT } 1500 / 40\end{array}$ & Schunk, Austria & $1500 \mathrm{~N}, 40 \mathrm{Nm}$ \\
\hline Motion analysis system & WinBiomechanics 1.2 & Zebris, Germany & \\
\hline X-ray fluoroscopy & BV25 & Phillips, Netherlands & \\
\hline
\end{tabular}

Table 1: The devices used, including the spine tester, six-component load cell, motion analysis system and X-ray fluoroscopy. 


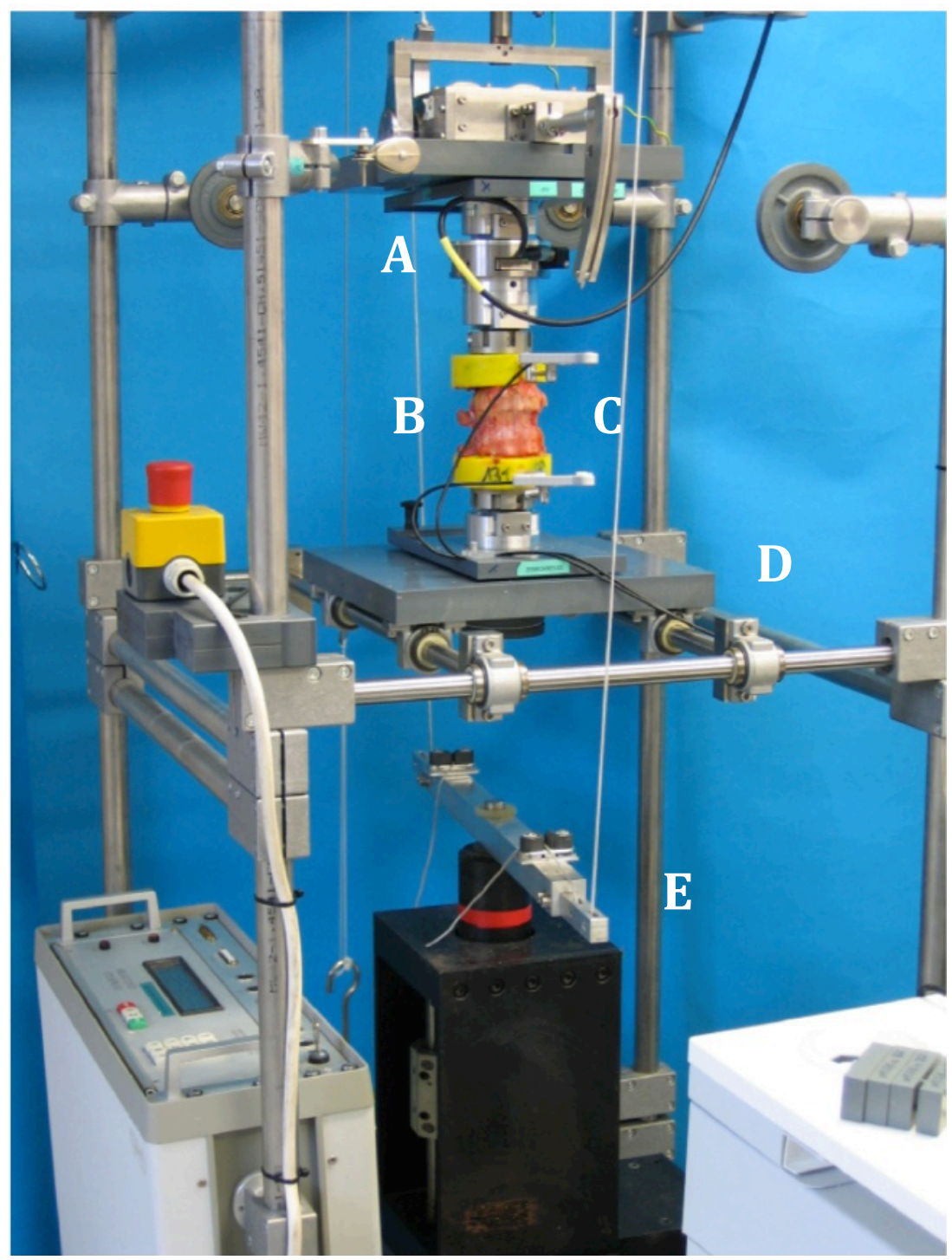

Figure 18: The spine tester (WiSi) with the six-component load cell (A), fixed specimen (B), motion analysis system (C), sliding carriage (D), and computer controlled stepper motor $(E)$.

\section{Cyclic Loading}

All cyclic loading was carried out in a servohydraulic materials testing machine (MTS 858 MiniBionix II; MTS Systems Corporation, Eden Prairie, Minnesota, USA). The specimens were loaded into a custom-made loading jig, which allowed eccentric loading of the specimens in flexion and had already been used for fracture creation (Figure 15). The specimens were 
loaded three times for 1000 sinusoidal cycles at $0.5 \mathrm{~Hz}$ using an increasing loading program with lower and upper load magnitudes of $50-250 \mathrm{~N}, 50$ $450 \mathrm{~N}$, and $50-650 \mathrm{~N}$.

\section{Test Sequences}

The following test sequences were conducted with all spinal specimens:

1. Flexibility test in the spine simulator - intact specimen

2. Fracture creation in the servohydraulic testing machine

3. Flexibility test in the spine simulator — fractured specimen (fr)

4. Stabilization (BKP/VBS)

5. Flexibility test in the spine simulator — treated specimen (tr)

6. Eccentric sinusoidal cyclic loading of the specimens in the materials testing machine (force-controlled 50-250 N for 1000 load cycles) (c1)

7. Flexibility test in the spine simulator (c1)

8. Eccentric sinusoidal cyclic loading of the specimens in the materials testing machine (force-controlled 50-450 N for 1000 load cycles) (c2)

9. Flexibility test in the spine simulator (c2)

10. Eccentric sinusoidal cyclic loading of the specimens in the materials testing machine (force-controlled 50-650 N for 1000 load cycles) (c3)

11. Flexibility test in the spine simulator (c3)

\section{Recorded Data}

Spine Simulator. The range of motion in the three main motion planes was used to evaluate the stability of the two stabilizing methods being investigated. During loading of the specimens, the parameters listed in 
Table 2 were recorded continuously. The recorded data were used to determine the following parameters (for the third load cycle) with positive and negative maximum moment:

Parameter

Abbreviation (unit)

Range of motion for pure moments of $7.5 \mathrm{Nm} \quad \mathrm{ROM}\left({ }^{\circ}\right)$

Forces in the cranial fixation $\quad F(N)$

Moments in the cranial fixation $\quad \mathrm{M}(\mathrm{Nm})$

Table 2: Parameters that were measured and calculated.

Cyclic Loading. The minimum and maximum displacements of the actuator were recorded during cyclic loading. To assess the subsidence of the specimens, the displacement at the lower cyclic load (50 N) was used for all three cyclic loading periods. The stiffness of the construct was evaluated using the displacement amplitude during the three cyclic loading periods (Table 3).

Parameter

Displacement at min cyclic load Displacement at max cyclic load Amplitude during cyclic load
Abbreviation (unit)

$$
\begin{aligned}
& D_{\min }(\mathrm{mm}) \\
& D_{\max }(\mathrm{mm}) \\
& A=\left(D_{\max }-D_{\min }\right)(\mathrm{mm})
\end{aligned}
$$

Table 3: Parameters that were measured and calculated.

\section{Input Parameters}

The names in the testing template used by the Spine Simulator software were sequentially noted on the test protocol for the specimens. For the motion analysis software, the following filenames were used to store the test sequences: $A A A B C C D D . z e b$, with the letters indicating: 
B Level of fracture; 1 for $L 1,2$ for T12

CC State of the specimen:

in, intact

fx, fracture

tr, treatment

c1, after cyclic loading 1

c2, after cyclic loading 2

c3, after cyclic loading 3

DD Direction of loading (xp, xn, yp, yn, zn, zp)

The filenames in cyclic loading included the specimen name and the range of the force-controlled cyclic loading.

\section{Data Analysis}

The data from the six-component load cell was also recorded in the file created by the motion capture software. The data were filtered to smoothen the hysteresis curves, and the third load cycle was cut and saved into a new file for data analysis. Motion characteristics during minimum and maximum loading with pure moments (flexion/extension, lateral bending and axial rotation) were evaluated using a matrix laboratory (MATLAB) routine (Figure 19). Only the data from the third cycle were evaluated. 


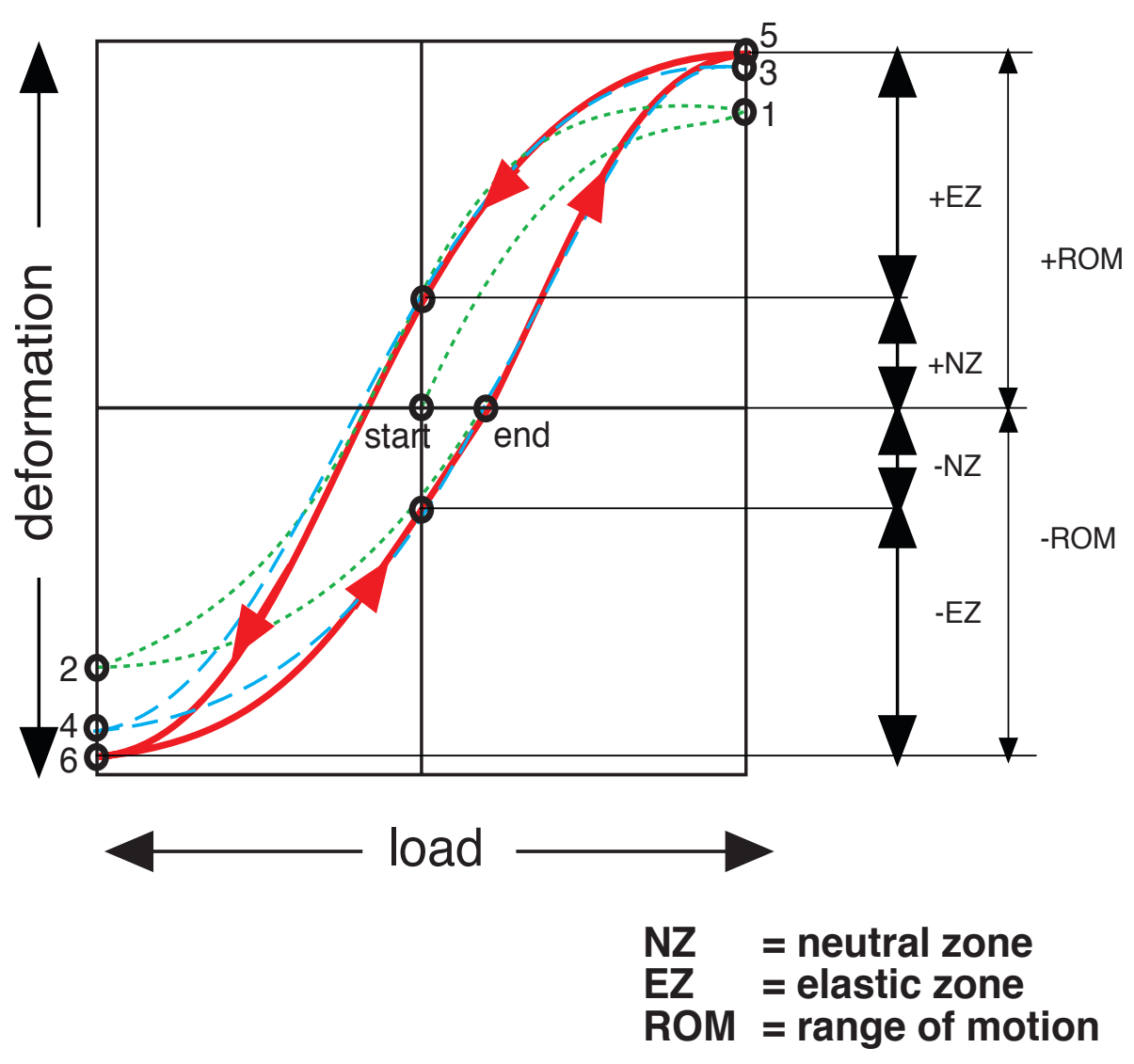

Figure 19: A typical load-displacement curve resulting from continuously changing flexion/extension moments $( \pm \mathrm{My})$, or left/right axial rotation moments $( \pm M z)$, or right/left lateral bending moments $( \pm M x)$.

\section{Radiographic Investigation}

Kyphosis angle during balloon inflation and deflation. To estimate the kyphosis angle, standardized radiographs were taken using fluoroscopy following each testing step. To allow reproducibility, the specimens were fixed to a radiography jig and eccentrically preloaded with $55 \mathrm{~N}$ (resulting in a flexion moment of approximately $2.5 \mathrm{Nm}$ ). The kyphosis angle was measured using the ICOview software program (ITH Icoserve Technology for Healthcare Ltd., Innsbruck, Austria). Vertebral kyphosis in the intact and fractured states 
was estimated (Figure 20). During reduction, lateral radiographs were taken after each 1-mL step of balloon inflation up to the maximum inflation of $5 \mathrm{~mL}$. The kyphosis angle following cement application was measured in order to reveal the deflation effect.

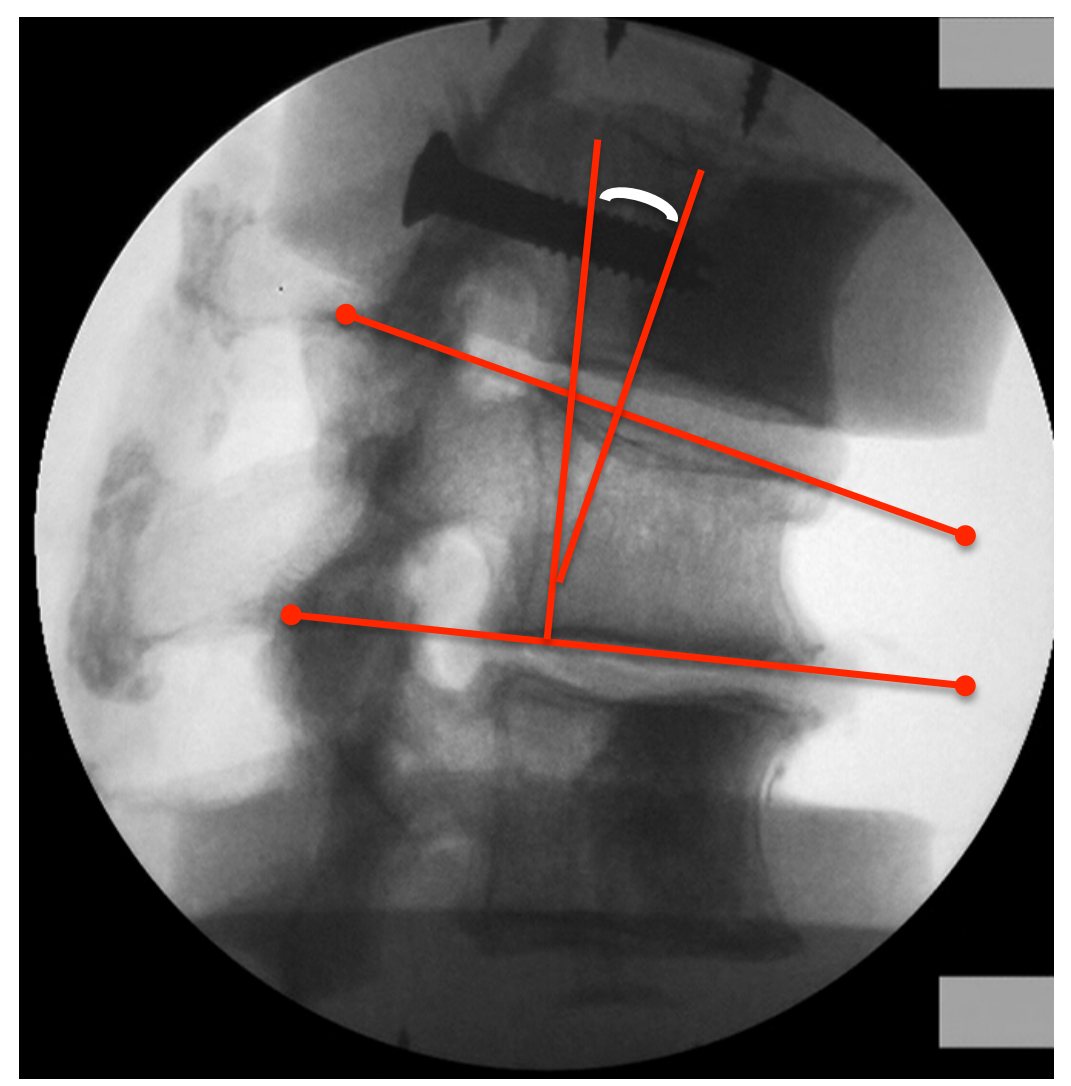

Figure 20: Measurement of segmental kyphosis angle in lateral fluoroscopic X-rays.

Kyphosis angle in the course of testing. The impact of cyclic loading on the loss of reduction was further estimated. The kyphosis angle was measured after each interval of cyclic loading using the set-up described above (Figure 21). 


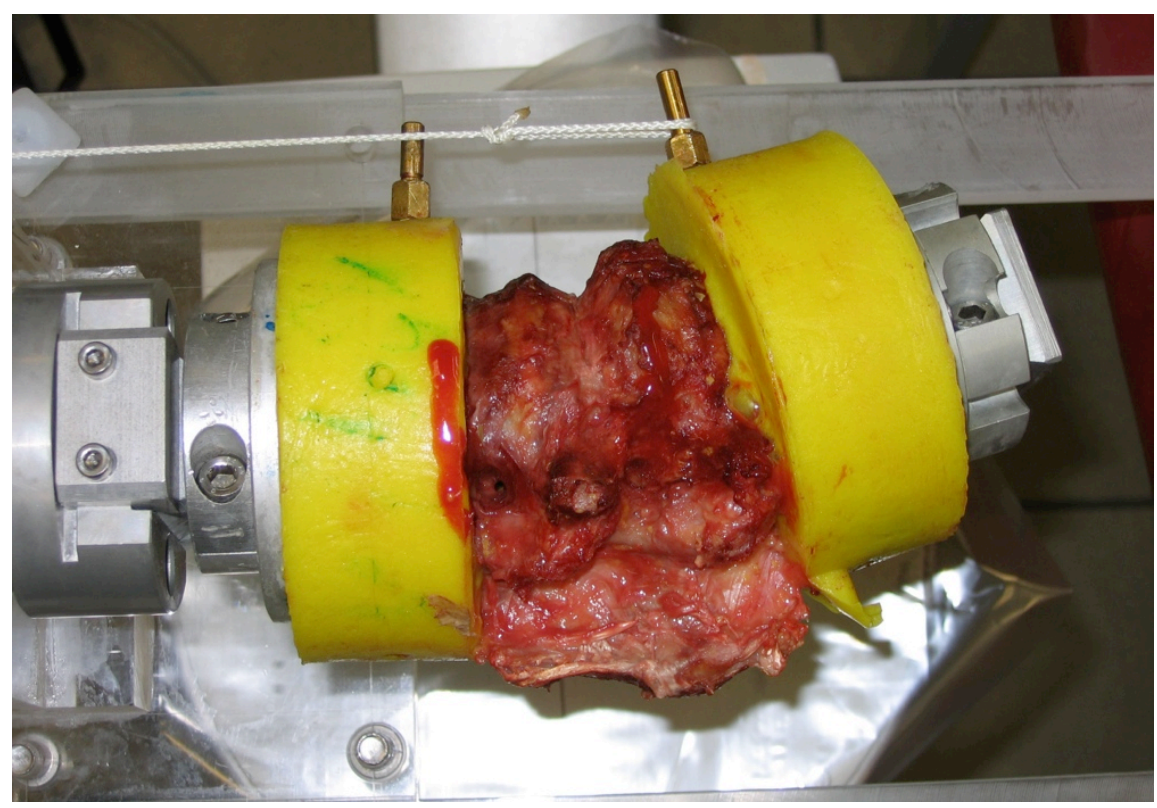

Figure 21: The X-ray jig with the eccentric loading device.

\section{Statistical Analysis}

Statistical analyses were carried out using the IBM SPSS Statistics program, version 21.0 (IBM Corporation, Armonk, New York, USA). The data and the results for range of motion (ROM) and kyphosis angle are reported as means with standard deviation (SD). A repeated-measurements analysis of variance (ANOVA) followed by a post-hoc Bonferroni test was carried out to analyze differences in the kyphosis angles and flexibility data. Significance was set at $P<0.05$ for all statistical test methods. 


\section{Results}

The test series was completed for all of the specimens and no gross implant failures were observed. The implanted materials stayed in the vertebral body through all the cycles, and the specimens were continuously checked fluoroscopically at the end of each testing step.

\section{Flexibility Tests (ROM)}

The ROM results are shown in Table 4.

\begin{tabular}{lcccr}
\hline & \multicolumn{2}{c}{ VBS } & \multicolumn{2}{c}{ BKP } \\
\cline { 2 - 5 } ROM $\left(^{\circ}\right)$ & Mean & SD & Mean & SD \\
\hline Intact & 12.5 & 1.1 & 11.9 & 6.0 \\
Fractured & 23.1 & 1.4 & 24.3 & 10.3 \\
Treated & 17.2 & 2.5 & 16.3 & 9.8 \\
Cyclic loading 1 & 18.8 & 2.3 & 19.4 & 10.0 \\
Cyclic loading 2 & 19.6 & 2.6 & 20.3 & 10.9 \\
Cyclic loading 3 & 20.8 & 3.6 & 20.9 & 11.3 \\
\hline
\end{tabular}

Table 4: Ranges of motion (ROM) in the different test sequences in the VBS and BKP treatment groups. The results are shown as means with standard deviation (SD).

The intact ROM for flexion/extension of the motion segments measured in all groups was $12.1^{\circ}\left(\mathrm{SD} 4.1^{\circ}\right)$. Following standardized fracturing, the ROM rose significantly to $23.7^{\circ}\left(\mathrm{SD} 7.0^{\circ}\right)$. After treatment, the ROM significantly declined in all groups, independently of the treatment, to $16.8^{\circ}\left(\mathrm{SD} 6.8^{\circ}\right)$ and did not reach the level in the intact specimens. During cyclic loading, the ROM measured in all three treatment groups increased steadily and was in the 
range of the fractured specimens at $20.8^{\circ}\left(\operatorname{SD~} 8.0^{\circ}\right)$ after the third period of cyclic loading. Following treatment, the flexibility of the specimens in all states (treatment, cyclic loading 1-3) differed significantly in comparison with the intact specimens. The differences between the treatment groups were small and not significant. Figure 22 shows the ROM during the course of testing, normalized relative to the intact state.

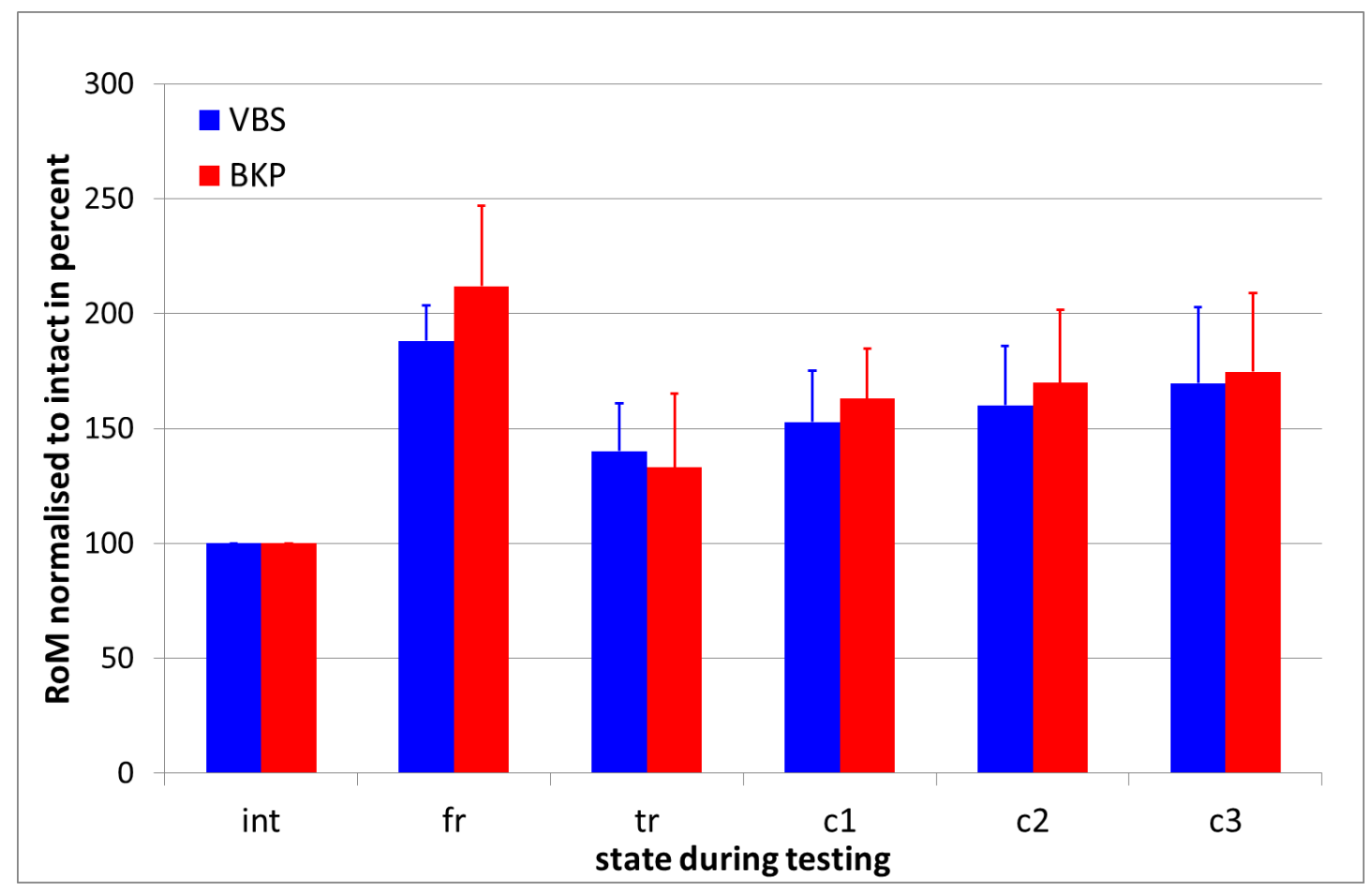

Figure 22: Range of motion (ROM) in flexion/extension in the different testing steps, normalized relative to the fractured state.

\section{Elastic Displacement and Height Loss during Cyclic Loading}

The elastic displacement of the specimens showed small but nonsignificant differences between the treatment groups throughout the three periods of cyclic loading (Figure 23). After the first period of cyclic loading (50-250 N), both groups showed a comparable range of elastic displacement, at $0.91 \mathrm{~mm}$ (SD 0.13) and $0.92 \mathrm{~mm}$ (SD 0.19) in the VBS and kyphoplasty groups, respectively. The displacement increased following the second period of cyclic 
loading (50-450 N) up to $1.58 \mathrm{~mm}(\mathrm{SD} 0.22)$ and $1.56 \mathrm{~mm}$ (SD 0.3), and after the third (50-650 N) to $2.02 \mathrm{~mm}(\mathrm{SD} 0.25)$ and $2.02 \mathrm{~mm}$ (SD 0.39) for VBS and BKP, respectively.

After the first period of cyclic loading, an equal height loss of $0.88 \mathrm{~mm}$ (SD 0.37 vs SD 0.32) was seen at the lower turning point of cyclic loading (50 N) in both groups. The height loss increased over the following load cycles to $3.69 \mathrm{~mm}(\mathrm{SD} \mathrm{1.15)}$ and $3.31 \mathrm{~mm}$ (SD 1.2), and to $6.33 \mathrm{~mm}$ (SD 1.71) and $5.67 \mathrm{~mm}$ (SD 1.82) in the VBS and BKP groups, respectively. However, none of the differences in height loss measured in the three groups was statistically significant.

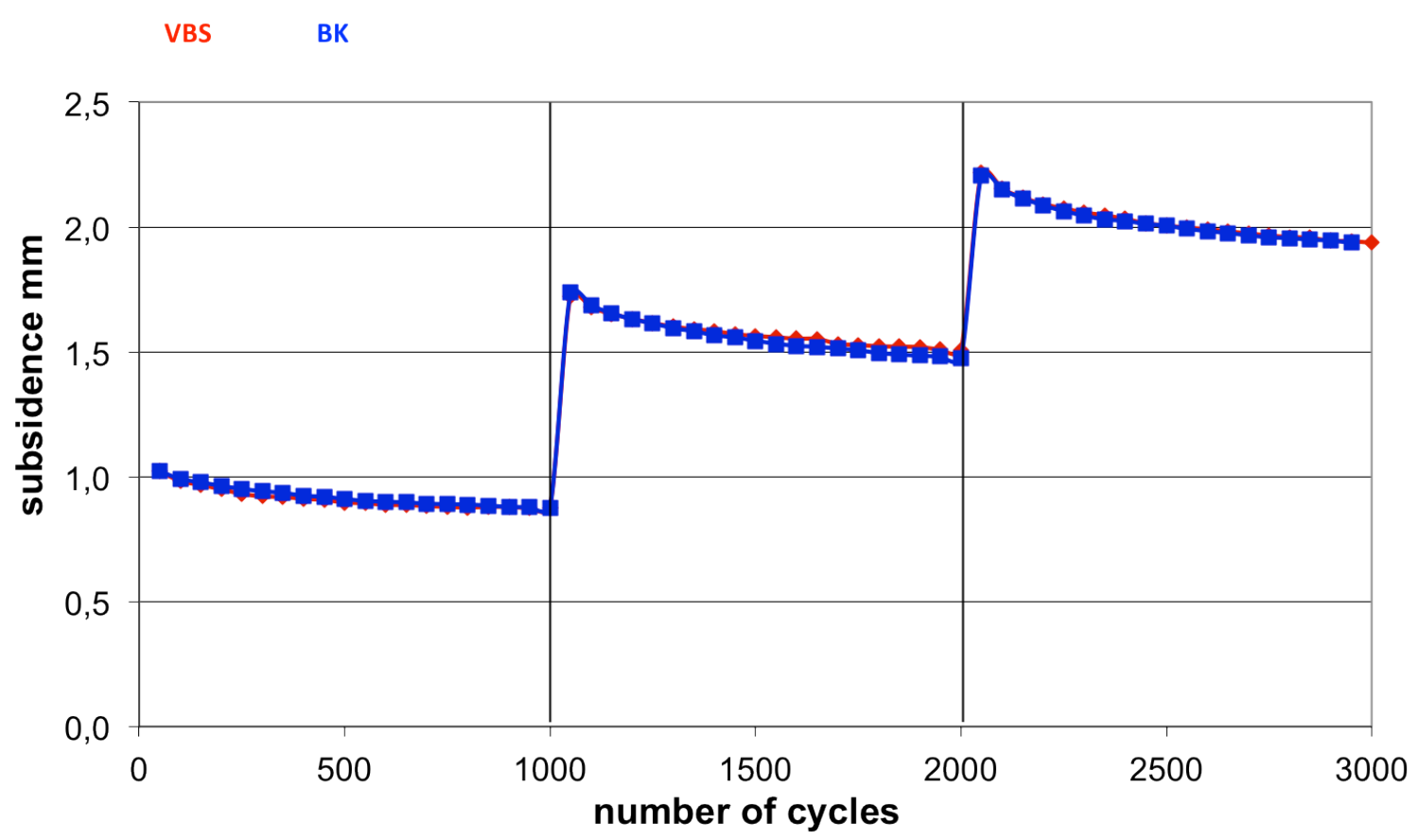

Figure 23: Elastic displacement during cyclic loading in the VBS (red) and BKP (blue) groups. 


\section{Radiographic Investigations}

Kyphosis angle during balloon inflation and deflation. During balloon inflation, the two techniques showed similar effects on the change in the kyphosis angle up to $5 \mathrm{~mL}$ of balloon filling. After inflation of the balloon to $5 \mathrm{~mL}$, BKP and VBS reduced the kyphosis angle by $6.0^{\circ}\left(\mathrm{SD} 3.2^{\circ}\right)$ and $5.9^{\circ}\left(\mathrm{SD} 1.9^{\circ}\right)$, respectively. On deflation of the balloon, $4.4^{\circ}\left(\mathrm{SD} 3.4^{\circ}\right)$ of the restored kyphosis angle was lost with kyphoplasty and $1.6^{\circ}$ (SD $\left.1.3^{\circ}\right)$ with VBS. This difference in the kyphosis loss after balloon deflation was significant (Figure 24).

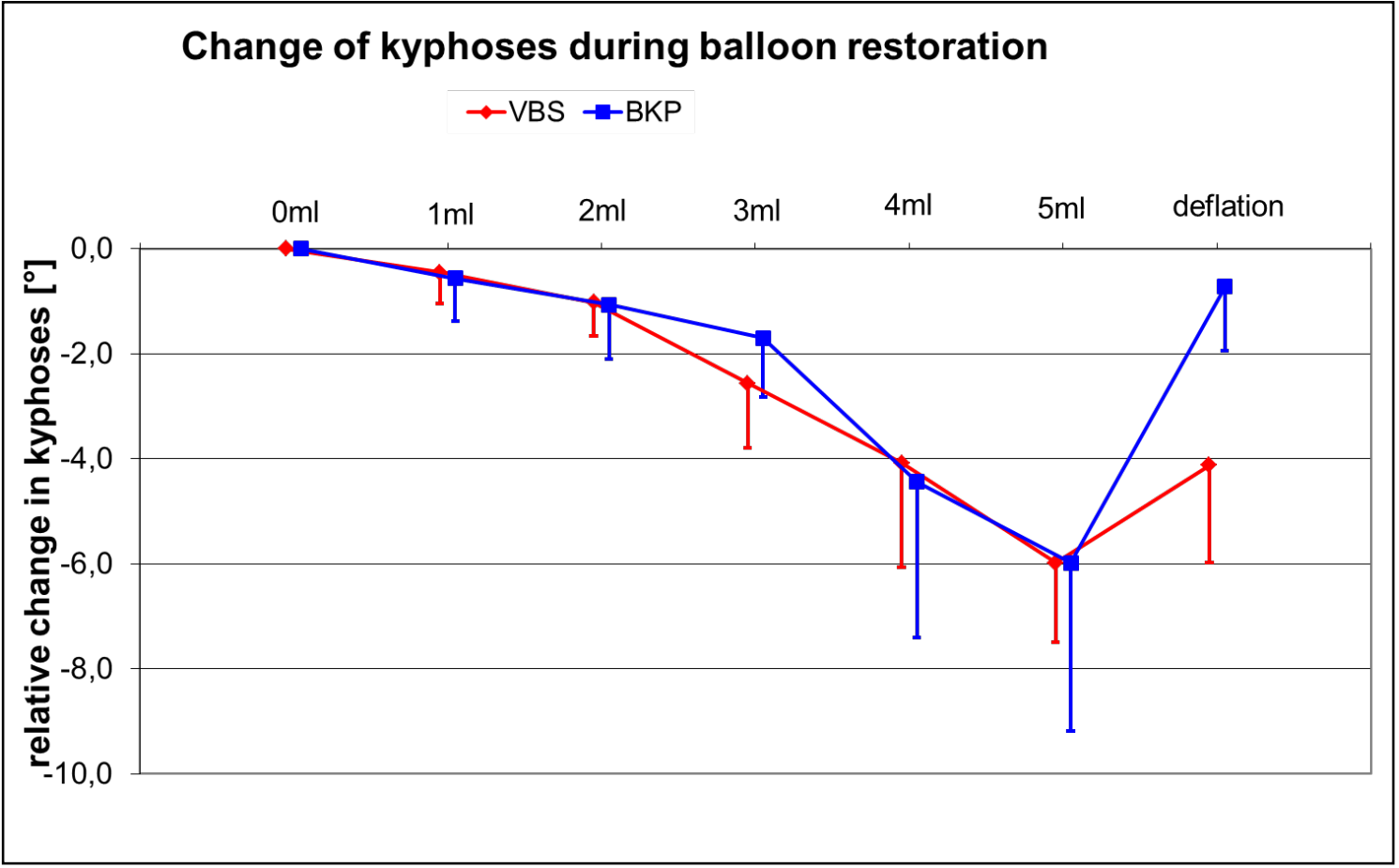

Figure 24: Relative changes in the kyphosis angle during balloon inflation and deflation after vertebral fracture for the VBS (red) and BKP (blue) groups. Kyphosis angle in the course of testing. Fracture creation had a comparable effect on all specimens in both groups. The kyphosis angle increased significantly up to $7.2^{\circ}\left(\operatorname{SD~} 3.3^{\circ}\right)$. According to the literature, this can be 
regarded as mild to moderate kyphotic deformation of the vertebral body (100). Both augmentation techniques led to significant reduction of the fracture. VBS treatment reduced the kyphosis by $3.3^{\circ}\left(\mathrm{SD} 1.2^{\circ}\right)$ and kyphoplasty reduced it by $1.9^{\circ}\left(\mathrm{SD} 1.4^{\circ}\right)$. The difference between the two treatment options was not significant. The reduction achieved showed no changes during cyclic loading. The results of the radiographic investigations for the development of the kyphotic angle during the course of testing are shown in Figure 25.



Figure 25: Relative changes in the kyphosis angle from the intact vertebrae in the course of the experiment for the VBS (red) and BKP (blue) groups.. 


\section{Discussion}

Conservative treatment is the primary choice in patients with spontaneous osteoporotic fractures. Pain reduction, rapid mobilization and medication to support bone metabolism are the first-line therapeutic regimens $(21,24,30$, 101-104). Further surgical treatment is indicated only in patients with persistent pain who are unable to achieve mobilization $(74,77,105,106)$. In contrast, fractures caused by trauma in osteoporotic bone are subject to the same diagnostic and therapeutic algorithms as other traumatic cases. Patients suffering from osteoporotic fractures often have a wide range of comorbid conditions. Minimally invasive surgical interventions, particularly cement augmentation, are an ideal option for treating these patients surgically, with minimum stress for the patients (107). In addition to providing rapid pain relief, major goals of surgery include avoidance of segmental and global deformities (30).

It has been recognized that the grade of therapeutic reduction in pathological spinal fractures is as important as that in nonosteoporotic fractures for avoiding the vicious circle of osteoporotic spinal column deformities (27). In osteoporotic bone, the acquired malaligned spinal curvature leads to rapid decompensation of spinal integrity, which becomes manifest in progressive deformation due to local redistribution of peak loads acting on a weak bone structure (32). Secondary subsidence and kyphotic deformity following vertebral structural breakdown due to osteoporosis are therefore major complications in the course of the disease and are directly associated with the patient's quality of life (87). 
Cement augmentation techniques were introduced in order to reduce the risks of progressive subsidence and avoid further complications. Following the introduction of kyphoplasty, its advantages in relation to safety and correction capacity rapidly became clear in comparison with vertebroplasty $(77,87)$ (108-111). For technical reasons, however, the effects of balloon deflation on the reduction result in the prone position, and in turn whether reduction can be maintained solely by bone cement (84) or using combinations of materials (112, 113), are as yet unclear. To investigate this, 12 thoracolumbar bisegmental human specimens that had been treated with balloon kyphoplasty (BKP) or vertebral body stenting (VBS) were biomechanically tested in a standardized fracture model in the present study. There were no significant differences between the two techniques with regard to the grade of reduction, but significant differences were observed for the subsequent balloon deflation effect, showing better reduction restoration with the VBS. As expected, neither technique was able to restore the stability of the intact state following treatment. With increasing loads, stability was markedly reduced to the level of the fractured specimen. Only slight differences between the techniques were found in relation to primary and secondary stability, as well as secondary subsidence. However, the ability of both of these augmentation techniques to achieve successful treatment of osteoporotic fractures has previously been demonstrated in vivo, in relation to pain reduction and rapid mobilization of patients $(21)$ - although reports on the amount of reduction and secondary height restoration achieved vary $(74,77,112)$. In biomechanical investigations in vitro and in clinical applications, it has been shown that following vertebral compression fractures, kyphoplasty leads to 
better height restoration in comparison with classical vertebroplasty $(87,114-$ 118), independently of whether the fracture has neoplastic causes (119) or osteoporotic causes (87). However, the restoration of the anterior and posterior walls achieved during balloon inflation is partly lost afterwards (113). This may be the result of a correction loss with variable preloads, through the following effect: if the balloon is deflated and the cement has not already been injected and cured, the cavity may collapse, depending on the existing preload and the structural configuration of the surrounding bone. To overcome this problem, new implant designs have been introduced in order to provide additional intermediate or final stability $(89,99,113,120)$ either with or without cement application.

The stent used for the VBS system is designed to resist existing preloads when the patient is in the prone position and should therefore limit the effect mentioned until the cement has been injected. In the present study, the effects of deflation differed significantly between kyphoplasty and the VBS system. The effect may have been amplified by the relatively high axial preload selected, which probably lies in the upper range of the forces acting in vivo. During reduction and fracture augmentation, this set-up emphasizes the deflation effect of the balloon, on the one hand, while it may also exceed the load-bearing capacity of the implanted stent on the other. The deflation effect can partly be compensated for through the subsequent cement application. This was demonstrated in a previous study, through the difference in the kyphosis angle resulting after treatment with the two techniques (100). The reduction capacity and the resulting quantity are strongly influenced by the underlying cement viscosity, as our own group has already shown (121). 
Transferred to clinical applications, hyperlordotic patient positioning should reduce preloading on the anterior spinal column. As a side effect, the greater tension on the anterior longitudinal ligament is able to passively reduce the existing fracture. However, depending on the localization and height of the fracture and the patient's physiognomy and stature, preloads inevitably vary substantially from case to case in reality. It appears difficult to neutralize these loads in all patients in order to achieve better reduction results and height restoration. This increases the need for active reduction options using appropriate devices.

In a recent clinical study, comparison of patients with osteoporotic compression fractures in the thoracolumbar spine who were treated with kyphoplasty or VBS showed no differences between the two groups with regard to the clinical outcome and height restoration (kyphotic angles $4.5^{\circ}$ for kyphoplasty and $4.7^{\circ}$ for VBS), although there was a higher complication rate in the VBS group (100). The study concerned, with evidence level I, shows how difficult it is to assign the different augmentation methods available to a heterogeneous group of patients and fractures that are still hard to differentiate. The success of treatment for spontaneous pathological fractures without relevant trauma - especially when there is multilevel involvement often depends on rapid pain reduction and patient mobilization $(74,107)$.

However, most of the published studies lack any analysis of spinal sagittal alignment. Lee et al. (31) were able to demonstrate that patients suffering from osteoporosis show sagittal spinopelvic parameters that are significantly different in comparison with control individuals. Further differences were found 
between patients with balanced and imbalanced osteoporosis with regard to age, bone mineral density in the lumbar spine and femoral neck, visual analogue scale, sacral slope and pelvic incidence. A recently published multicenter study including 1044 patients with osteoporosis demonstrated that osteoporotic vertebral fractures had significantly lower lumbar lordosis, sacral slope and pelvic incidence. The risk of a vertebral fracture was associated with bone marrow density in the lumbar spine, lumbar lordosis and pelvic incidence (32). Altered trunk muscle activation in patients with greater thoracic kyphosis was found to be an additional cofactor. The authors concluded that these patients have an altered balance efficacy, resulting in a greater compressive load on the spine. In combination with osteoporosis, this situation may even contribute to the pathogenesis of fractures $(33,34)$.

While intrasegmental stabilization and correction in spontaneous osteoporotic fractures can be securely achieved by cement augmentation $(85,122)$ the surgical restoration of the overall impairment of sagittal alignment requires multisegmental surgical correction (123). In contrast, fractures of osteopenic bone resulting from a relevant trauma mechanism normally show greater intrasegmental kyphosis, combined with a slight overall alignment imbalance (112). The latter type of fracture therefore requires even more local kyphosis correction. In a prospective multicenter study, Diel et al. reported promising results using VBS for osteoporotic and nonosteoporotic fractures (124). The authors concluded that the indication for applying a vertebral augmentation technique should be based not only on the fracture type, patient characteristics, and extrusion risk. Their results underline the importance of preoperative vertebral body deformity and its influence on the restoration 
potential. The study concludes that kyphoplasty is more appropriate in patients with mild deformities (kyphotic angle $8.5^{\circ}$ ) and recommends VBS for more severe preoperative deformities (kyphotic angle $17^{\circ}$ ) (124). In comparison with these results, the in-vitro study presented here was conducted using standardized fractures with mild deformation (100). This may be the reason for the only small divergence between the restoration effects of kyphoplasty and VBS using this set-up. In addition, if the restoration is underestimated, the deflation effect of the balloon may also be underestimated. This point needs to be taken into account in future investigations.

The ROM values and stiffness measurements achieved in the present study are comparable with those described in previous publications $(99,121)$, with no differences between the two augmentation techniques. However, the use of bisegmental specimens involves loading two intervertebral discs adjacent to the index vertebra. Accurate information about segmental stability may be limited with this method, particularly since the cyclic loading protocol involved continuous loading of the discs, causing progressive fluid loss.

Biomechanical testing set-ups for the spine, which are reduced to the bone and ligament structures, have known limitations $(125,126)$. In particular, they do not allow the influence of highly up-regulated and down-regulated musculotendinous systems on biomechanical characteristics to be evaluated. Despite the high level of standardization, it is still difficult to transfer the results obtained to the clinical situation and it is also difficult to compare them with those of other in-vitro studies, due to varying specimen characteristics (age, 
BMD, spinal level, species) and testing conditions. In addition, the influence of secondary factors such as tissue healing and bony ingrowth cannot be investigated in ex-vivo experiments. None the less, biomechanical in-vitro testing can be used to assess the initial influence of implants on the primary and secondary stability of a spinal segment that has been treated.

The results obtained using the biomechanical test set-up described here show slightly better height restoration and deflation effects with VBS in mildly to moderately deformed wedge fractures. No differences were evident between kyphoplasty and VBS with regard to primary and secondary stability or subsidence. In future studies, investigation of more severe fractures (kyphotic deformities) might be able to identify more pronounced differences between the techniques. 


\section{References}

1. Galbusera $F$, van Rijsbergen $M$, Ito K, Huyghe JM, Brayda-Bruno M, Wilke HJ. Ageing and degenerative changes of the intervertebral disc and their impact on spinal flexibility. European spine journal : official publication of the European Spine Society, the European Spinal Deformity Society, and the European Section of the Cervical Spine Research Society 2014; 23 Suppl 3:S324-32

2. Aebi M. Classification of thoracolumbar fractures and dislocations. European spine journal : official publication of the European Spine Society, the European Spinal Deformity Society, and the European Section of the Cervical Spine Research Society 2010; 19 Suppl 1:S2-7

3. Filis AK, Aghayev KV, Doulgeris JJ, Gonzalez-Blohm SA, Vrionis FD. Spinal neoplastic instability: biomechanics and current management options. Cancer control : journal of the Moffitt Cancer Center 2014; 21:144-50

4. Fisher CG, DiPaola CP, Ryken TC, Bilsky MH, Shaffrey $\mathrm{Cl}$, et al. A novel classification system for spinal instability in neoplastic disease: an evidence-based approach and expert consensus from the Spine Oncology Study Group. Spine 2010; 35:E1221-9

5. Panjabi MM, Lydon C, Vasavada A, Grob D, Crisco JJ, 3rd, Dvorak J. On the understanding of clinical instability. Spine (Phila Pa 1976) 1994; 19:2642-50

6. Panjabi MM, Hausfeld JN, White AA, 3rd. A biomechanical study of the ligamentous stability of the thoracic spine in man. Acta orthopaedica Scandinavica 1981; 52:315-26

7. Panjabi MM, White AA, 3rd, Keller D, Southwick WO, Friedlaender G. Stability of the cervical spine under tension. Journal of biomechanics 1978; 11:189-97

8. Panjabi MM, Yamamoto I, Oxland TR, Crisco JJ, Freedman D. Biomechanical stability of five pedicle screw fixation systems in a 
human lumbar spine instability model. Clinical biomechanics 1991; $6: 197-205$

9. Wilke HJ, Wenger $\mathrm{K}$, Claes L. Testing criteria for spinal implants: recommendations for the standardization of in vitro stability testing of spinal implants. European spine journal : official publication of the European Spine Society, the European Spinal Deformity Society, and the European Section of the Cervical Spine Research Society 1998; $7: 148-54$

10. Panjabi MM. Biomechanical evaluation of spinal fixation devices: I. A conceptual framework. Spine 1988; 13:1129-34

11. Panjabi MM, Abumi K, Duranceau J, Crisco JJ. Biomechanical evaluation of spinal fixation devices: II. Stability provided by eight internal fixation devices. Spine 1988; 13:1135-40

12. Wilke HJ, Claes L, Schmitt H, Wolf S. A universal spine tester for in vitro experiments with muscle force simulation. European spine journal : official publication of the European Spine Society, the European Spinal Deformity Society, and the European Section of the Cervical Spine Research Society 1994; 3:91-7

13. Wilke HJ, Mehnert $U$, Claes LE, Bierschneider MM, Jaksche $H$, Boszczyk BM. Biomechanical evaluation of vertebroplasty and kyphoplasty with polymethyl methacrylate or calcium phosphate cement under cyclic loading. Spine 2006; 31:2934-41

14. Adams MA, Bogduk N, Burton K, Dolan P. 2006. The Biomechanics of Back Pain. Edingburgh, London, New York: Churchill Livingstone

15. Hansen JT. 2014. Netter's Clinical Anatomy. St. Louis/ USA: Saunders W.B., Elsevier

16. Briggs AM, Wrigley TV, van Dieen JH, Phillips B, Lo SK, et al. The effect of osteoporotic vertebral fracture on predicted spinal loads in vivo. European spine journal : official publication of the European Spine Society, the European Spinal Deformity Society, and the European Section of the Cervical Spine Research Society 2006; 15:1785-95

17. Vaccaro AR, Oner C, Kepler CK, Dvorak M, Schnake K, et al. AOSpine thoracolumbar spine injury classification system: fracture description, neurological status, and key modifiers. Spine 2013; 38:2028-37 
18. Denis $F$. The three column spine and its significance in the classification of acute thoracolumbar spinal injuries. Spine 1983; 8:81731

19. Denis F. Spinal instability as defined by the three-column spine concept in acute spinal trauma. Clinical orthopaedics and related research 1984:65-76

20. Adams MA, Dolan P. Spine biomechanics. J Biomech 2005; 38:197283

21. Papanastassiou ID, Phillips FM, Van Meirhaeghe J, Berenson JR, Andersson GB, et al. Comparing effects of kyphoplasty, vertebroplasty, and non-surgical management in a systematic review of randomized and non-randomized controlled studies. European spine journal : official publication of the European Spine Society, the European Spinal Deformity Society, and the European Section of the Cervical Spine Research Society 2012; 21:1826-43

22. Kaloostian PE, Yurter A, Etame AB, Vrionis FD, Sciubba DM, Gokaslan ZL. Palliative strategies for the management of primary and metastatic spinal tumors. Cancer control : journal of the Moffitt Cancer Center $2014 ; 21: 140-3$

23. Kassamali RH, Ganeshan A, Hoey ET, Crowe PM, Douis H, Henderson J. Pain management in spinal metastases: the role of percutaneous vertebral augmentation. Annals of oncology : official journal of the European Society for Medical Oncology / ESMO 2011; 22:782-6

24. Colon-Emeric CS, Saag KG. Osteoporotic fractures in older adults. Best practice \& research. Clinical rheumatology 2006; 20:695-706

25. King $A B$, Saag KG, Burge RT, Pisu M, Goel N. Fracture Reduction Affects Medicare Economics (FRAME): impact of increased osteoporosis diagnosis and treatment. Osteoporos Int 2005; 16:154557

26. Dennison E, Cooper C. Epidemiology of osteoporotic fractures. Hormone research 2000; 54 Suppl 1:58-63

27. Cockerill W, Ismail AA, Cooper C, Matthis C, Raspe H, et al. Does location of vertebral deformity within the spine influence back pain and 
disability? European Vertebral Osteoporosis Study (EVOS) Group. Annals of the rheumatic diseases 2000; 59:368-71

28. Kaptoge S, Armbrecht G, Felsenberg D, Lunt M, O'Neill TW, et al. When should the doctor order a spine X-ray? Identifying vertebral fractures for osteoporosis care: results from the European Prospective Osteoporosis Study (EPOS). Journal of bone and mineral research : the official journal of the American Society for Bone and Mineral Research 2004; 19:1982-93

29. Vergnaud P, Lunt M, Scheidt-Nave C, Poor G, Gennari C, et al. Is the predictive power of previous fractures for new spine and non-spine fractures associated with biochemical evidence of altered bone remodelling? The EPOS study. European Prospective Osteoporosis Study. Clinica chimica acta; international journal of clinical chemistry $2002 ; 322: 121-32$

30. Heini PF. The current treatment--a survey of osteoporotic fracture treatment. Osteoporotic spine fractures: the spine surgeon's perspective. Osteoporosis international : a journal established as result of cooperation between the European Foundation for Osteoporosis and the National Osteoporosis Foundation of the USA 2005; 16 Suppl 2:S85-92

31. Lee JS, Lee HS, Shin JK, Goh TS, Son SM. Prediction of sagittal balance in patients with osteoporosis using spinopelvic parameters. European spine journal : official publication of the European Spine Society, the European Spinal Deformity Society, and the European Section of the Cervical Spine Research Society 2013; 22:1053-8

32. Dai J, Yu X, Huang S, Fan L, Zhu G, et al. Relationship between sagittal spinal alignment and the incidence of vertebral fracture in menopausal women with osteoporosis: a multicenter longitudinal follow-up study. European spine journal : official publication of the European Spine Society, the European Spinal Deformity Society, and the European Section of the Cervical Spine Research Society 2014;

33. Briggs AM, Greig AM, Bennell KL, Hodges PW. Paraspinal muscle control in people with osteoporotic vertebral fracture. European spine journal : official publication of the European Spine Society, the 
European Spinal Deformity Society, and the European Section of the Cervical Spine Research Society 2007; 16:1137-44

34. Greig AM, Briggs AM, Bennell KL, Hodges PW. Trunk muscle activity is modified in osteoporotic vertebral fracture and thoracic kyphosis with potential consequences for vertebral health. PloS one 2014; 9:e109515

35. Rohlmann A, Zander T, Bergmann G. Spinal loads after osteoporotic vertebral fractures treated by vertebroplasty or kyphoplasty. European spine journal : official publication of the European Spine Society, the European Spinal Deformity Society, and the European Section of the Cervical Spine Research Society 2006; 15:1255-64

36. Cho Y, Lee G, Aguinaldo J, Lee KJ, Kim K. Correlates of bone mineral density and sagittal spinal balance in the aged. Annals of rehabilitation medicine 2015; 39:100-7

37. Rao RD, Singrakhia MD. Painful osteoporotic vertebral fracture. Pathogenesis, evaluation, and roles of vertebroplasty and kyphoplasty in its management. The Journal of bone and joint surgery. American volume 2003; 85-A:2010-22

38. Leidig G, Minne HW, Sauer P, Wuster C, Wuster J, et al. A study of complaints and their relation to vertebral destruction in patients with osteoporosis. Bone and mineral 1990; 8:217-29

39. Voormolen MH, Mali WP, Lohle PN, Fransen H, Lampmann LE, et al. Percutaneous vertebroplasty compared with optimal pain medication treatment: short-term clinical outcome of patients with subacute or chronic painful osteoporotic vertebral compression fractures. The VERTOS study. AJNR. American journal of neuroradiology 2007; 28:555-60

40. Fourney DR, Frangou EM, Ryken TC, Dipaola CP, Shaffrey Cl, et al. Spinal instability neoplastic score: an analysis of reliability and validity from the spine oncology study group. Journal of clinical oncology : official journal of the American Society of Clinical Oncology 2011; 29:3072-7

41. Reinhold M, Knop C, Beisse R, Audige L, Kandziora F, et al. Operative treatment of 733 patients with acute thoracolumbar spinal injuries: comprehensive results from the second, prospective, Internet-based 
multicenter study of the Spine Study Group of the German Association of Trauma Surgery. Eur Spine J 19:1657-76

42. Knop C, Reinhold M, Roeder C, Staub L, Schmid R, et al. Internet based multicenter study for thoracolumbar injuries: a new concept and preliminary results. Eur Spine J 2006; 15:1687-94

43. Sundaresan N, Boriani S, Rothman A, Holtzman R. Tumors of the osseous spine. J Neurooncol 2004; 69:273-90

44. Tomita K, Kawahara N, Kobayashi T, Yoshida A, Murakami H, Akamaru T. Surgical strategy for spinal metastases. Spine 2001; 26:298-306

45. Schaser KD, Melcher I, Mittlmeier T, Schulz A, Seemann JH, et al. [Surgical management of vertebral column metastatic disease.]. Unfallchirurg 2007; 110:137-62

46. Hammerberg KW. Surgical treatment of metastatic spine disease. Spine 1992; 17:1148-53

47. Harrington KD. Anterior decompression and stabilization of the spine as a treatment for vertebral collapse and spinal cord compression from metastatic malignancy. Clin Orthop Relat Res 1988:177-97

48. Holman PJ, Suki D, McCutcheon I, Wolinsky JP, Rhines LD, Gokaslan ZL. Surgical management of metastatic disease of the lumbar spine: experience with 139 patients. J Neurosurg Spine 2005; 2:550-63

49. Ibrahim A, Crockard A, Antonietti P, Boriani S, Bunger C, et al. Does spinal surgery improve the quality of life for those with extradural (spinal) osseous metastases? An international multicenter prospective observational study of 223 patients. Invited submission from the Joint Section Meeting on Disorders of the Spine and Peripheral Nerves, March 2007. J Neurosurg Spine 2008; 8:271-8

50. Schaser KD, Melcher I, Mittlmeier T, Schulz A, Seemann JH, et al. [Surgical management of vertebral column metastatic disease]. Der Unfallchirurg 2007; 110:137-59; quiz 60-1

51. Goodrich JT. History of spine surgery in the ancient and medieval worlds. Neurosurg Focus 2004; 16:E2

52. The classic: the original paper appeared in the New York Medical Journal 93:1013, 1911. I. An operation for progressive spinal 
deformities: a preliminary report of three cases from the service of the orthopaedic hospital. Clin Orthop Relat Res 1964; 35:4-8

53. The classic. Transplantation of a portion of the tibia into the spine for Pott's disease. A preliminary report. Jama, 57: 885, 1911. Clin Orthop Relat Res 1972; 87:5-8

54. Hibbs RA. An operation for progressive spinal deformities: a preliminary report of three cases from the service of the orthopaedic hospital. 1911. Clin Orthop Relat Res 2007; 460:17-20

55. Wiltse L. 1987. History of Lumbar Spine Stabilization. In Lumbar Spine Surgery, ed. AWe al. St. Louis: C.V. Mosby.

56. Roy-Camille R, Saillant G, Mazel C. Plating of thoracic, thoracolumbar, and lumbar injuries with pedicle screw plates. Orthop Clin North Am $1986 ; 17: 147-59$

57. JWS M. Raymon Roy-Camille, M.D. 1927-1994. J Bone Joint Surg Am 1996; 78-A:1449

58. Hodgson AR, Stock FE, Fang HS, Ong GB. Anterior spinal fusion. The operative approach and pathological findings in 412 patients with Pott's disease of the spine. Br J Surg 1960; 48:172-8

59. Denis F. The three column spine and its significance in the classification of acute thoracolumbar spinal injuries. Spine 1983; 8:81731

60. Wang F, Zhu Y. Treatment of complete fracture-dislocation of thoracolumbar spine. Journal of spinal disorders \& techniques 2013; 26:421-6

61. Coe JD, Warden KE, Herzig MA, McAfee PC. Influence of bone mineral density on the fixation of thoracolumbar implants. A comparative study of transpedicular screws, laminar hooks, and spinous process wires. Spine 1990; 15:902-7

62. Gilbert SG, Johns PC, Chow DC, Black RC. Relation of vertebral bone screw axial pullout strength to quantitative computed tomographic trabecular bone mineral content. J Spinal Disord 1993; 6:513-21

63. Halvorson TL, Kelley LA, Thomas KA, Whitecloud TS, 3rd, Cook SD. Effects of bone mineral density on pedicle screw fixation. Spine 1994; $19: 2415-20$ 
64. Ashman RB, Bechtold JE, Edwards WT, Johnston CE, 2nd, McAfee PC, Tencer AF. In vitro spinal arthrodesis implant mechanical testing protocols. J Spinal Disord 1989; 2:274-81

65. Cummings SR, Melton LJ. Epidemiology and outcomes of osteoporotic fractures. Lancet 2002; 359:1761-7

66. Ferguson SJ, Winkler F, Nolte LP. Anterior fixation in the osteoporotic spine: cut-out and pullout characteristics of implants. Eur Spine $J$ 2002; $11: 527-34$

67. Roy DK, O'Neill TW, Finn JD, Lunt M, Silman AJ, et al. Determinants of incident vertebral fracture in men and women: results from the European Prospective Osteoporosis Study (EPOS). Osteoporos Int 2003; 14:19-26

68. Curtis R, Goldhahn J, Schwyn R, Regazzoni P, Suhm N. Fixation principles in metaphyseal bone--a patent based review. Osteoporos Int 2005; 16 Suppl 2:S54-64

69. Disch AC, Knop C, Schaser KD, Blauth M, Schmoelz W. Angular stable anterior plating following thoracolumbar corpectomy reveals superior segmental stability compared to conventional polyaxial plate fixation. Spine 2008; 33:1429-37

70. Deramond H, Depriester C, Galibert P, Le Gars D. Percutaneous vertebroplasty with polymethylmethacrylate. Technique, indications, and results. Radiol Clin North Am 1998; 36:533-46

71. Galibert P, Deramond H, Rosat P, Le Gars D. [Preliminary note on the treatment of vertebral angioma by percutaneous acrylic vertebroplasty]. Neurochirurgie 1987; 33:166-8

72. Alvarez L, Alcaraz M, Perez-Higueras A, Granizo JJ, de Miguel I, et al. Percutaneous vertebroplasty: functional improvement in patients with osteoporotic compression fractures. Spine 2006; 31:1113-8

73. Chen JF, Lee ST. Percutaneous vertebroplasty for treatment of thoracolumbar spine bursting fracture. Surgical neurology 2004; 62:494-500; discussion

74. Feltes C, Fountas KN, Machinis T, Nikolakakos LG, Dimopoulos V, et al. Immediate and early postoperative pain relief after kyphoplasty 
without significant restoration of vertebral body height in acute osteoporotic vertebral fractures. Neurosurgical focus 2005; 18:e5

75. Garfin SR, Buckley RA, Ledlie J, Balloon Kyphoplasty Outcomes G. Balloon kyphoplasty for symptomatic vertebral body compression fractures results in rapid, significant, and sustained improvements in back pain, function, and quality of life for elderly patients. Spine 2006; $31: 2213-20$

76. Gaitanis IN, Hadjipavlou AG, Katonis PG, Tzermiadianos MN, Pasku DS, Patwardhan AG. Balloon kyphoplasty for the treatment of pathological vertebral compressive fractures. Eur Spine J 2005; $14: 250-60$

77. Heini PF, Orler R. Kyphoplasty for treatment of osteoporotic vertebral fractures. European spine journal : official publication of the European Spine Society, the European Spinal Deformity Society, and the European Section of the Cervical Spine Research Society 2004; 13:184-92

78. Schmoelz W, Disch AC, Huber JF. Vertebroplasty with self-locking hexagonal metal implants shows comparable primary and secondary stiffness to PMMA cement augmentation techniques in a biomechanical vertebral compression fracture model. Eur Spine $J$ 19:1029-36

79. Fourney DR, Schomer DF, Nader R, Chlan-Fourney J, Suki D, et al. Percutaneous vertebroplasty and kyphoplasty for painful vertebral body fractures in cancer patients. J Neurosurg 2003; 98:21-30

80. Mehbod A, Aunoble S, Le Huec JC. Vertebroplasty for osteoporotic spine fracture: prevention and treatment. Eur Spine J 2003; 12 Suppl 2:S155-62

81. Nouda S, Tomita S, Kin A, Kawahara K, Kinoshita M. Adjacent vertebral body fracture following vertebroplasty with polymethylmethacrylate or calcium phosphate cement: biomechanical evaluation of the cadaveric spine. Spine (Phila Pa 1976) 2009; $34: 2613-8$ 
82. Baroud G, Vant C, Wilcox R. Long-term effects of vertebroplasty: adjacent vertebral fractures. Journal of long-term effects of medical implants 2006; 16:265-80

83. Wang HK, Lu K, Liang CL, Weng HC, Wang KW, et al. Comparing clinical outcomes following percutaneous vertebroplasty with conservative therapy for acute osteoporotic vertebral compression fractures. Pain medicine 2010; 11:1659-65

84. Lieberman IH, Togawa D, Kayanja MM. Vertebroplasty and kyphoplasty: filler materials. The spine journal : official journal of the North American Spine Society 2005; 5:305S-16S

85. Boger A, Heini P, Windolf M, Schneider E. Adjacent vertebral failure after vertebroplasty: a biomechanical study of low-modulus PMMA cement. European spine journal : official publication of the European Spine Society, the European Spinal Deformity Society, and the European Section of the Cervical Spine Research Society 2007; $16: 2118-25$

86. Kasperk C, Hillmeier J, Noldge G, Grafe IA, Dafonseca K, et al. Treatment of painful vertebral fractures by kyphoplasty in patients with primary osteoporosis: a prospective nonrandomized controlled study. Journal of bone and mineral research : the official journal of the American Society for Bone and Mineral Research 2005; 20:604-12

87. Li X, Yang H, Tang T, Qian Z, Chen L, Zhang Z. Comparison of kyphoplasty and vertebroplasty for treatment of painful osteoporotic vertebral compression fractures: twelve-month follow-up in a prospective nonrandomized comparative study. Journal of spinal disorders \& techniques 2012; 25:142-9

88. Belkoff SM, Mathis JM, Fenton DC, Scribner RM, Reiley ME, Talmadge K. An ex vivo biomechanical evaluation of an inflatable bone tamp used in the treatment of compression fracture. Spine $2001 ; 26: 151-6$

89. Heini PF, Teuscher R. Vertebral body stenting / stentoplasty. Swiss medical weekly 2012; 142:w13658

90. Panjabi MM. Biomechanical evaluation of spinal fixation devices: I. A conceptual framework. Spine 1988; 13:1129-34 
91. Panjabi MM, Abumi K, Duranceau J, Crisco JJ. Biomechanical evaluation of spinal fixation devices: II. Stability provided by eight internal fixation devices. Spine 1988; 13:1135-40

92. Panjabi MM, Oxland TR, Kifune M, Arand M, Wen L, Chen A. Validity of the three-column theory of thoracolumbar fractures. A biomechanic investigation. Spine 1995; 20:1122-7

93. Panjabi MM, Wrathall JR. Biomechanical analysis of experimental spinal cord injury and functional loss. Spine 1988; 13:1365-70

94. Wilke HJ, Jungkunz B, Wenger K, Claes LE. Spinal segment range of motion as a function of in vitro test conditions: effects of exposure period, accumulated cycles, angular-deformation rate, and moisture condition. The Anatomical record 1998; 251:15-9

95. Schmoelz W, Disch AC, Huber JF. Vertebroplasty with self-locking hexagonal metal implants shows comparable primary and secondary stiffness to PMMA cement augmentation techniques in a biomechanical vertebral compression fracture model. European spine journal : official publication of the European Spine Society, the European Spinal Deformity Society, and the European Section of the Cervical Spine Research Society 2010; 19:1029-36

96. Bergot C, Laval-Jeantet AM, Hutchinson K, Dautraix I, Caulin F, Genant HK. A comparison of spinal quantitative computed tomography with dual energy X-ray absorptiometry in European women with vertebral and nonvertebral fractures. Calcified tissue international $2001 ; 68: 74-82$

97. Panjabi MM, Krag M, Summers D, Videman T. Biomechanical timetolerance of fresh cadaveric human spine specimens. Journal of orthopaedic research : official publication of the Orthopaedic Research Society 1985; 3:292-300

98. Kettler A, Schmoelz W, Shezifi $Y$, Ohana N, Ben-Arye A, et al. Biomechanical performance of the new BeadEx implant in the treatment of osteoporotic vertebral body compression fractures: restoration and maintenance of height and stability. Clinical biomechanics 2006; 21:676-82 
99. Schmoelz W, Disch AC, Huber JF. Vertebroplasty with self-locking hexagonal metal implants shows comparable primary and secondary stiffness to PMMA cement augmentation techniques in a biomechanical vertebral compression fracture model. Eur Spine $J$ 2012; 19:1029-36

100. Werner CM, Osterhoff G, Schlickeiser J, Jenni R, Wanner GA, et al. Vertebral body stenting versus kyphoplasty for the treatment of osteoporotic vertebral compression fractures: a randomized trial. The Journal of bone and joint surgery. American volume 2013; 95:577-84

101. Diamond TH, Champion B, Clark WA. Management of acute osteoporotic vertebral fractures: a nonrandomized trial comparing percutaneous vertebroplasty with conservative therapy. The American journal of medicine 2003; 114:257-65

102. Katscher S, Verheyden P, Gonschorek O, Glasmacher S, Josten C. [Thoracolumbar spine fractures after conservative and surgical treatment. Dependence of correction loss on fracture level]. Der Unfallchirurg 2003; 106:20-7

103. Park JH, Kang KC, Shin DE, Koh YG, Son JS, Kim BH. Preventive effects of conservative treatment with short-term teriparatide on the progression of vertebral body collapse after osteoporotic vertebral compression fracture. Osteoporosis international : a journal established as result of cooperation between the European Foundation for Osteoporosis and the National Osteoporosis Foundation of the USA $2014 ; 25: 613-8$

104. Song D, Meng B, Gan M, Niu J, Li S, et al. The incidence of secondary vertebral fracture of vertebral augmentation techniques versus conservative treatment for painful osteoporotic vertebral fractures: a systematic review and meta-analysis. Acta radiologica 2014;

105. Papanastassiou ID, Filis A, Aghayev K, Kokkalis ZT, Gerochristou MA, Vrionis FD. Adverse prognostic factors and optimal intervention time for kyphoplasty/vertebroplasty in osteoporotic fractures. BioMed research international 2014; 2014:925683 
106. Kumar K, Nguyen R, Bishop S. A comparative analysis of the results of vertebroplasty and kyphoplasty in osteoporotic vertebral compression fractures. Neurosurgery 2010; 67:ons171-88; discussion ons 88

107. Zampini JM, White AP, McGuire KJ. Comparison of 5766 vertebral compression fractures treated with or without kyphoplasty. Clinical orthopaedics and related research 2010; 468:1773-80

108. Kasperk C, Noldge G, Grafe I, Meeder P, Huber F, Nawroth P. [Indications and results of kypho- and vertebroplasty]. Der Internist 2008; 49:1206, 8-10, 12-18

109. Kim MJ, Lindsey DP, Hannibal M, Alamin TF. Vertebroplasty versus kyphoplasty: biomechanical behavior under repetitive loading conditions. Spine 2006; 31:2079-84

110. Liu JT, Liao WJ, Tan WC, Lee JK, Liu CH, et al. Balloon kyphoplasty versus vertebroplasty for treatment of osteoporotic vertebral compression fracture: a prospective, comparative, and randomized clinical study. Osteoporosis international : a journal established as result of cooperation between the European Foundation for Osteoporosis and the National Osteoporosis Foundation of the USA 2010; 21:359-64

111. Yan D, Duan L, Li J, Soo C, Zhu H, Zhang Z. Comparative study of percutaneous vertebroplasty and kyphoplasty in the treatment of osteoporotic vertebral compression fractures. Archives of orthopaedic and trauma surgery $2011 ; 131: 645-50$

112. Klezl Z, Majeed H, Bommireddy R, John J. Early results after vertebral body stenting for fractures of the anterior column of the thoracolumbar spine. Injury 2011; 42:1038-42

113. Korovessis P, Vardakastanis K, Repantis T, Vitsas V. Balloon kyphoplasty versus KIVA vertebral augmentation--comparison of 2 techniques for osteoporotic vertebral body fractures: a prospective randomized study. Spine 2013; 38:292-9

114. Kim MJ, Lindsey DP, Hannibal M, Alamin TF. Vertebroplasty versus kyphoplasty: biomechanical behavior under repetitive loading conditions. Spine 2006; 31:2079-84 
115. McCann H, LePine M, Glaser J. Biomechanical comparison of augmentation techniques for insufficiency fractures. Spine 2006; 31:E499-502

116. Steinmann J, Tingey CT, Cruz G, Dai Q. Biomechanical comparison of unipedicular versus bipedicular kyphoplasty. Spine 2005; 30:201-5

117. Tomita S, Molloy S, Jasper LE, Abe M, Belkoff SM. Biomechanical comparison of kyphoplasty with different bone cements. Spine 2004; 29:1203-7

118. Wilke HJ, Mehnert U, Claes LE, Bierschneider MM, Jaksche $H$, Boszczyk BM. Biomechanical evaluation of vertebroplasty and kyphoplasty with polymethyl methacrylate or calcium phosphate cement under cyclic loading. Spine 2006; 31:2934-41

119. Julka A, Tolhurst SR, Srinivasan RC, Graziano GP. Functional Outcomes and Height Restoration for Patients With Multiple MyelomaRelated Osteolytic Vertebral Compression Fractures Treated With Kyphoplasty. J Spinal Disord Tech

120. Belkoff SM, Mathis JM, Fenton DC, Scribner RM, Reiley ME, Talmadge K. An ex vivo biomechanical evaluation of an inflatable bone tamp used in the treatment of compression fracture. Spine $2001 ; 26: 151-6$

121. Ruger M, Schmoelz W. Vertebroplasty with high-viscosity polymethylmethacrylate cement facilitates vertebral body restoration in vitro. Spine 2009; 34:2619-25

122. Voggenreiter G. Balloon kyphoplasty is effective in deformity correction of osteoporotic vertebral compression fractures. Spine 2005; 30:280612

123. Pradhan BB, Bae HW, Kropf MA, Patel VV, Delamarter RB. Kyphoplasty reduction of osteoporotic vertebral compression fractures: correction of local kyphosis versus overall sagittal alignment. Spine 2006; 31:435-41

124. Diel P, Roder C, Perler G, Vordemvenne T, Scholz M, et al. Radiographic and safety details of vertebral body stenting: results from a multicenter chart review. BMC musculoskeletal disorders 2013; $14: 233$ 
125. Oda I, Cunningham BW, Abumi K, Kaneda K, McAfee PC. The stability of reconstruction methods after thoracolumbar total spondylectomy. An in vitro investigation. Spine 1999; 24:1634-8

126. Shannon FJ, DiResta GR, Ottaviano D, Castro A, Healey JH, Boland PJ. Biomechanical analysis of anterior poly-methyl-methacrylate reconstruction following total spondylectomy for metastatic disease. Spine 2004; 29:2096-12 


\section{Legends to Figures}

Figure 1: Thoracic, thoracolumbar and lumbar cross-sectional illustrations of the spinal column, with neighboring structures (15).

Figure 2: In this example, the body weight $W$ exerts a flexor moment of $\mathrm{W} \times \mathrm{dW}$ around the center of rotation "O" in the middle of the L5/S1 disc space. No movement is possible if this is balanced by the extensor moment $\mathrm{F} \times \mathrm{dF}$ generated by the back muscles (14).

Figure 3: An example of a force-deformation graph in biological tissue (14). "Toe region": deformation increases rapidly with increasing force, indicating that the stiffness of the specimen is low. "Linear region": the stiffness is approximately constant at higher loads. "Elastic limit": the stiffness begins to decline, indicating initial damage to the specimen. "Ultimate failure": stiffness falls to zero. The force at this point is the "strength" of the specimen.

Figure 4: Orientation of trabeculae in different sagittal sections. Trabeculae from the pedicles reinforce the vertebral endplates (above). Trabeculae in the midsagittal plane are orientated more symmetrically (below). Adapted from Adams et al. (14).

Figure 5: The complete lateral spine in a healthy control individual (left) and in a patient suffering from osteoporosis (right), showing sagittal balance (left) side and an imbalanced alignment (right) (31).

Figure 6: The three different patterns of osteoporotic fracture of the vertebral body associated with specific pathogenetic conditions. From top to bottom: wedge fracture, biconcave fracture, vertebral body collapse (37). 
Figure 7: A 62-year-old woman suffering from a T12 fracture (lateral and anteroposterior radiographs, left side) in osteoporotic bone. Treatment with vertebral body stenting was carried out (lateral and anteroposterior radiographs, right side).

Figure 8: The intraoperative set-up, with a patient lying in prone position on a carbon table and two fluoroscopes for simultaneous lateral and anteroposterior $\mathrm{x}$-ray viewing.

Figure 9: Intraoperative fluoroscopic evaluation of the transpedicular path into the vertebral body, with anatomic boundaries. Anteroposterior view of the pedicle (red circles); lateral view with pedicle borders, area below the fractured endplate and anterior wall (author's own archive).

Figure 10: An inflated kyphoplasty balloon (left; Medtronic Inc., Minneapolis, Minnesota, USA) and an expanded vertebral body stent (right; DePuySynthes Ltd., Zuchwil, Switzerland). Both systems are available in different sizes adapted to the different spinal levels.

Figure 11: Kyphoplasty (left) and vertebral body stenting (right) inflation systems. The manometer displays the measured pressure actually acting in the system in psi (pounds per square inch) and atm (atmospheres).

Figure 12: The international definition of the coordinate axes in the spine, showing possible translations and rotations along the coordinate axes according to Wilke et al. (12).

Figure 13: A spine simulator with six degrees of freedom for in-vitro biomechanical testing. The green arrows indicate the possible axial 
translations, the yellow arrows show possible axial rotations and the red arrows show the direction of load application with tension cables connected to a computer-controlled stepper motor.

Figure 14: Fatigue curve, showing the reduction of strength with the number of cyclic loading procedures. The fatigue limit is a threshold in some materials, below which loading will never lead to failure (14).

Figure 15: Fracture creation and cyclic loading in the servohydraulic materials testing machine. The loading jig is connected to the testing machine with two ball-and-socket connections. On the dorsal side of the loading jig, the two loading plates are connected to the rods with two hinge joints to ensure loading in flexion.

Figure 16: X-ray series of a specimen treated with kyphoplasty (from left to right): 1) intact specimen, 2) following fracture creation, 3) balloon placement, 4) balloon inflation, 5) following balloon deflation and 6) cement augmentation.

Figure 17: X-ray series of a specimen treated with VBS (from left to right): 1) intact specimen, 2) following fracture creation, 3) stent placement, 4) balloon inflation, 5) following balloon deflation with expanded stent and 6) following cement augmentation.

Figure 18: The spine tester (WiSi) with the six-component load cell $(\mathrm{A})$, fixed specimen (B), motion analysis system (C), sliding carriage (D), and computer controlled stepper motor (E). 
Figure 19: A typical load-displacement curve resulting from continuously changing flexion/extension moments $( \pm \mathrm{My})$, or left/right axial rotation moments $( \pm M z)$, or right/left lateral bending moments $( \pm M x)$.

Figure 20: Measurement of segmental kyphosis angle in lateral fluoroscopic X-rays.

Figure 21: The X-ray jig with the eccentric loading device.

Figure 22: Range of motion (ROM) in flexion/extension in the different testing steps, normalized relative to the fractured state.

Figure 23: Elastic displacement during cyclic loading in the VBS (112) and BKP (blue) groups.

Figure 24: Relative changes in the kyphosis angle during balloon inflation and deflation after vertebral fracture.

Figure 25: Relative changes in the kyphosis angle from the intact vertebrae in the course of the experiment. 


\section{Legends to Tables}

Table 1: The devices used, including the spine tester, six-component load cell, motion analysis system and X-ray fluoroscopy.

Table 2: Parameters that were measured and calculated.

Table 3: Parameters that were measured and calculated.

Table 4: Ranges of motion (ROM) in the different test sequences in the VBS and BKP treatment groups. The results are shown as means with standard deviation (SD). 


\section{Abbreviations}

Listed as they appear in the text.

\begin{tabular}{|c|c|c|}
\hline BKP & $=$ & Balloon Kyphoplasty \\
\hline VBS & $=$ & Vertebral Body Stenting \\
\hline $\mathrm{T}$ & $=$ & Thoracic vertebra \\
\hline L & $=$ & Lumbar vertebra \\
\hline $\mathrm{g} / \mathrm{cm}^{3}$ & $=$ & Gram per cubic centimeter \\
\hline $\mathrm{Nm}$ & $=$ & Newtonmeter \\
\hline ROM & $=$ & Range of motion \\
\hline$P$ & $=$ & P-value \\
\hline FSU & $=$ & Functional spinal unit \\
\hline $\mathrm{kg}$ & $=$ & Kilogram \\
\hline f & $=$ & Force \\
\hline $\mathrm{m}$ & $=$ & Mass \\
\hline g & $=$ & Acceleration \\
\hline$N$ & $=$ & Newton \\
\hline $\mathrm{MPa}$ & $=$ & Megapascal $\left(=1 \mathrm{~N} / \mathrm{mm}^{2}\right)$ \\
\hline $\mathrm{m}$ & $=$ & Meter \\
\hline $\mathrm{m} / \mathrm{s}$ & $=$ & Meter per second \\
\hline $\mathrm{m} / \mathrm{s}^{2}$ & $=$ & Meter per square second \\
\hline BMD & $=$ & Bone mineral density \\
\hline EPOS & $=$ & European Prospective Osteoporosis Study \\
\hline EVOS & $=$ & European Vertebral Osteoporosis Study \\
\hline VAS & $=$ & Visual Analogue Scale \\
\hline $\mathrm{AO}$ & $=$ & Arbeitsgemeinschaft Osteosynthesefragen \\
\hline
\end{tabular}




\begin{tabular}{|c|c|c|}
\hline DGOU & $=$ & $\begin{array}{l}\text { Deutsche Gesellschaft für Orthopädie und } \\
\text { Unfallchirurgie }\end{array}$ \\
\hline VBR & $=$ & Vertebral body replacement \\
\hline EFP & $=$ & European forearm phantom \\
\hline $\mathrm{mg} / \mathrm{cm}^{3}$ & $=$ & Miligram per cubic centimeter \\
\hline PMMA & $=$ & Polymethymetacrylate \\
\hline MTS & $=$ & Material testing machine \\
\hline WiSi & $=$ & Spine-simulator \\
\hline $\mathrm{mm} / \mathrm{min}$ & $=$ & Milimeter per minute \\
\hline SD & $=$ & Standard deviation \\
\hline $\mathrm{fr}$ & $=$ & Fractured state \\
\hline $\operatorname{tr}$ & $=$ & Treated state \\
\hline c1 & $=$ & State following first cyclic loading \\
\hline $\mathrm{c} 2$ & $=$ & State following second cyclic loading \\
\hline c3 & $=$ & State following third cyclic loading \\
\hline Dmin & $=$ & Minimum displacement \\
\hline Dmax & $=$ & Maximum displacement \\
\hline A & $=$ & Amplitude \\
\hline $\mathrm{F}$ & $=$ & Force \\
\hline M & $=$ & Moments \\
\hline My & $=$ & Moments in flexion/extension \\
\hline $\mathrm{Mz}$ & $=$ & Moments in axial rotation \\
\hline Mx & $=$ & Moments in lateral bending \\
\hline$\circ$ & $=$ & Angle in degrees \\
\hline
\end{tabular}


The following publication had to be removed for online access of this thesis.

Cement Augmentation in a Thoracolumbar Fracture Model: Reduction and Stability After Balloon Kyphoplasty Versus Vertebral Body Stenting

Disch, Alexander C. MD*; Schmoelz, Werner $\mathrm{PhD}^{\dagger}$

In: Spine

01 September 2014 - Volume 39 - Issue 19 - p E1147-E1153

doi: $10.1097 / B R S .0000000000000470$

Biomechanics 


\section{Declaration of Authorship}

I hereby declare that the $\mathrm{PhD}$ thesis submitted here was in all parts exclusively prepared on my own, and that other resources or other means (including electronic media and online sources) than those explicitly referred to have not been utilized.

All quoted fragments of text, employed in a literal and/or analogous manner, have been marked as such.

Berlin, April 1st, 2015

Alexander Disch 